\title{
Demographic and economic factors of labour supply: Long-term projections and policy options for France, Germany, Italy and the United Kingdom ${ }^{1}$
}

\author{
Serguey Ivanov*
}

\begin{abstract}
The paper presents labour supply scenarios in France, Germany, Italy and the United Kingdom for the years 2025 and 2050. These projections were based on the examination of the dynamics of the major contributing factors to the labour supply (LS), i.e. working-age population (WAP), labour force participation rate (LFPR), employment rate (ER) and labour utilisation (LU; defined as time worked per worker per year). The assumptions underlying the scenarios varied from plausible to 'best case scenario' to unrealistic. In France and in the United Kingdom, the demographic factors coupled with continuing immigration at the current levels will shape only a marginal decrease of the size of WAP. By contrast, the size of Germany's and Italy's WAP will shrink significantly by 2025 and, barring a tremendous surge in immigration, greatly by mid-century. In order to sustain the supply of labour, Italy has to eliminate unemployment. This assumes the sustainability of such factors as the recent increase in LFPR (especially of women) and relatively large immigration. By contrast, Germany has a large potential for increasing labour utilisation. Unless, however, immigration is increased dramatically, this will not suffice to balance the impact of the WAP decrease on LS. Within varying degrees, governments are able to affect the components of labour supply and capitalise on eventual synergies. The analysis relies on data from the United Nations Population Division, OECD, ILO and the European Union.
\end{abstract}

\footnotetext{
1 The views expressed are those of the author and are not necessarily those of the United Nations.

* Serguey Ivanov, Department of Economics and Social Affairs, United Nations Secretariat DC21904, New York, NY 10017, USA. Email: Ivanov@un.org
} 


\section{Introduction}

It might seem odd to raise the issue of looming labour shortages in the time of massive unemployment. One may argue, however, that large-scale unemployment is transitory while demographic trends are resilient.

The next two decades belie labour force dynamics that are completely determined by past population reproduction, save migration inflows. Capital and technology as factors of production command most attention when the demographics of the labour force are steady and satisfactory, while population declines tend to shift the focus towards labour.

This paper focuses on the projected contraction of working-age populations (WAP) in France, Germany, Italy and the United Kingdom, as well as on the options to sustain the supply of labour (LS). As all papers in this domain, it starts with an exposition of the largely unavoidable demographic results of low fertility. The potentials of immigration, increased participation in the labour force and employment to balance the negative demographic developments are considered.

In addition to these factors, this paper includes labour utilisation (working time) as a determinant of labour supply. This factor has been built into some models (e.g. Boulhol 2009), which focused on current inter-country variations rather than future developments. Our projection scenarios explicitly point to adjustment options that are differently suited to actual combinations of demographic and non-demographic factors. Comparing four large countries of the European Union that significantly differ with respect to all included variables serves to further sharpen the results.

The 1-10 year horizons that are typically used for employment projections are appropriate for appraising the trends that are driven by economic factors only or with respect to official goals such as the Lisbon strategy (Feld 2006). Demography provides a much longer-term vision that may yield different results. Looking at a more distant future is important, as the contraction of the labour force (which has already begun) will greatly accelerate in the future, and especially in the second quarter of the century.

Long-term projections make sense, because the trends in WAP during 20252050 will be determined and based essentially on fertility assumptions for the 2010-2035 period, migration patterns notwithstanding. There are only minor disagreements among experts about these assumptions.

Relevant demographic trends include population ageing and the negative growth (i.e. decrease) of the population in total (depopulation) or of particular age groups. Sometimes ageing is supposed to be synonymous with population decline. In fact, no peaceful contraction of population takes place without ageing; population decline follows and accompanies advanced ageing. However, ageing itself does not necessarily entail negative population growth. The whole demographic transition is associated with increasing the population's median age, 
which, in essence, is 'ageing'. It follows that using the terms 'ageing' and 'population decrease' interchangeably is incorrect.

While ageing is a very significant process affecting the supply of labour in its own right, here it is dealt with only tangentially. The supply of labour is determined by demographic and economic factors. The demographic factors consist of the natural reproduction of the labour force and migrations. Among economic factors, the most important are the inclusion of the relevant age and sex groups into labour force, the actual employment of the labour force and the extent of use of potentially available working time.

It is not our goal to impose a view that a contracting labour supply is an inherently negative phenomenon. There is an opinion that this is not even a problematic issue because the economy will simply adjust to a smaller labour force through diminished consumer demand. Besides, the capital-work ratio will increase, spurring productivity growth. From the vantage point of global sustainable development a smaller national economy is beneficial. Several counterarguments, however, can be advanced.

The world of contracting national economies may be a hospitable world, yet it will definitively sail in uncharted waters. For instance, negative population growth may limit economic output of the European Union economies, while the steadily increasing labour supply in the United States will serve to fuel its economic growth. Conversely, demographics may become a powerful stimulus for creating new engines of growth for the economies of Europe. New and unknown challenges may arise from the coexistence of contracting and expanding economies within integrated economic spaces such as the European Union. Shrinking national budgets may call for new criteria and new regulations for the public sector.

According to the European Commission, a massive decline in the number of employed people will have a huge impact on the overall economic growth, the functioning of the internal market and the competitiveness of the firms on the European Union (European Commission 2005). Sustained negative economic growth presents fundamental ideological and macroeconomic challenges. Modern economies function on the presumption of expansion; they are fundamentally oriented to growth and every deviation from the ascending path is universally blamed for hurting economic growth. Governments, businesses, civil society and media-we all share the paradigm that growth is benign, that decline is malignant, that expansion is healthy and contraction is morbid, that growing gross domestic product equals prosperity, and that a dropping output spells weakness, crisis and hardship.

Sustaining the usual pace of economic growth when labour supply is shrinking may be achieved through accelerated growth of labour productivity. This would be a challenging task. Since a portion (and, under particular conditions, quite a large portion) of incremental labour productivity will be 'used' 
to offset the losses of labour supply, the remainder may not suffice to assure economic growth.

There may be other specific arguments against a contracting labour force. Working-age populations are contracting faster than general populations, which depresses the production per capita and, therefore, average well-being. Despite the signs of population change, ageing creates additional demand for labourintensive services, thereby compounding the deficit and draining other sectors.

A shrinking population means shrinking markets with lower demand for labour. Yet, labour supply to some large economic sectors, such as physical infrastructure, is inelastic. As a result, the effect of a large-scale contraction of the labour force may not be limited to just a downsizing of the economy, but could provoke serious imbalances. In addition, in several sectors the systematic contractions of the labour force should be followed by a decommissioning of productive capacities, in turn causing significant economic losses.

We will not, however, delve much deeper into these issues, for our goal here is different. It is to demonstrate how the demographic factors depress the supply of labour and how the economic factors may be used to balance this contraction. It follows that, within this text, such adjectives as 'negative' or 'positive' should only be interpreted within the context of the perspective described above.

We combine brief overviews of the trends in the factors of labour supply with scenarios for the future that are based on a series of demographic and economic assumptions. Labour supply (LS) is projected as employed labour force (LF) and total time worked in the national economy (TT). Four indicators are factored into the projections: working-age population (WAP) defined as population aged 15-64; labour force participation rates (LFPR, or economic activity rates); employment rates (ER) and labour utilisation (LU). The latter is defined as time worked per worker per year. Hence, WAP is the function of natural reproduction of population and net migration, whereas LS may be decomposed either as

$$
\begin{aligned}
& L F=W A P \cdot L F P R \cdot E R, \text { or } \\
& T T=L F \cdot L U
\end{aligned}
$$

The interactions between migrations and the natural reproduction of a population are incorporated in the demographic projection model. On the contrary, we did not estimate other interactions in spite of the fact that they are relevant to projecting labour supply. Some of these interactions are cursorily touched upon in the last section.

Past population estimates and five variants of population projections (medium, low, high and constant-fertility, all with migration, as well as a medium variant without migration) come from World Population Prospects DEMOBASE of the United Nations Population Division. Other variants have been generated by applying different assumptions to DEMOBASE data. Unless indicated otherwise, 
labour statistics are from OECDStat. Net migration is presented in absolute numbers. WAP, LF and TT are normalised as indices with the baseline in 2010.

Estimates are framed by 2005-2010 at the high end and 1970 or 1985 at the low end. The benchmark year is 2010. Technically, 2010 is still in the future. However, these differences are minor and the ensuing uncertainty has so little impact on our computations that it is ignored. The simulation scenarios are presented for two points in time: 2025 and 2050. The latter date is the horizon of the United Nations population projections. It is a fact that the mid-century is not that extravagant a time horizon even for non-demographic trends, as governments do develop practical plans for such time frames. For instance, the United Kingdom adopted a scheme of shifting the retirement age by 2046. The former date (2025) is chosen because the youngest already born cohort will enter into working age some time around 2025 and the labour supply will, therefore, not be affected by future fertility until that date.

We use a simple sequence of steps to evaluate the demographic trends and to estimate the options to balance their outcomes. First, we explore what the supply of labour would be, provided that it is driven by fertility only, everything else being held constant. Then we estimate the impact of three migration scenarios: zero migration, net migration factored into the United Nations projections (roughly equivalent to the observed net migration prior to recent hikes) and the migration needed to stabilise WAP. At the third stage, we assess the extent to which higher aggregate levels of labour participation (resulting essentially from the recent increase of female labour could, if sustained during the lifespan and across cohorts, offset the contraction of WAP or even become a substitute for immigration. Fourthly, we address the impact of unemployment on the availability of labour. Finally, we open the subject of labour utilisation as a source for closing the gap in labour supply created by demographic trends. This leads to a discussion on selected policy implications.

Indeed, aggregate indicators yield very rough and perhaps biased estimates because all labour characteristics are age- and gender-specific while the age structure of the labour force is changing. The ILO, OECD and the European Central Bank use refined methodologies to project labour force participation disaggregated by age and sex (see overview in Carone 2005). However, in order to consistently apply this approach within the scope of this paper would entail disaggregating all parameters of labour supply, including time worked. The data on average workweek by sex and age are available from Eurostat, but converting them into explicit estimates of time worked per year would require using assumptions that might be too bold. This paper circumvents this difficulty by not attempting to disaggregate all parameters. Instead, we try to combine (a) our own estimates of the aggregate WAP resulting from age-sex distributions, both with and without net migration (b) aggregate LFPR projections implemented by a cohort approach (Carone 2005) and (c) aggregate levels of ER and LU from OECDStat, which are implicitly based on age-sex specific rates. The results 
obtained by Carone (2005) are based on Eurostat population projections and, therefore, are not exactly compatible with age-sex distributions from United Nations population projections, yet these discrepancies are marginal. The assumptions of stable future ER and LU used for the benchmark scenarios are likely to be more biased since ageing tends to depress these indicators. We did not attempt to introduce corrections for these biases.

\section{Fertility}

The dynamics of working-age populations are shaped by fertility, mortality and migrations. Together with the population size and age structure fertility determines the size of WAP. Moreover, age structure itself is primarily determined by fertility. Increased child, adolescent and adult survival rates in the second half of the 20th century did contribute to WAP growth in all of the four European countries. This impact, however, falls outside the scope of this paper because in the future the role of mortality decline in these ages is likely to become marginal. The role of international migrations is country-specific.

Over the last 60 years there have been dissimilarities of fertility trends, yet it is the commonalities that have prevailed (Figure 1). Most Western countries have experienced transient simultaneous fertility increases that culminated in the baby boom. Around 1960, fertility was significantly higher than replacement level in all four countries ranging from 2.4 in Italy and Germany to 2.8 in France and the United Kingdom. Since the mid-1960s in France, Germany and the United Kingdom, and after since the early 1970s in Italy, fertility has been falling precipitously. In the mid-1980s, in France and the United Kingdom the decline has halted and total fertility has stabilised at 1.8-1.9.

This recovery is driven by the near-completion of the transition from early to late childbearing (i.e, diminishing tempo effect) as well as by some quantum effects caused by economic factors. This leads to the expectation that in the lowest-low fertility countries, cohort and (with a lag) period fertility will re-enter the 1.5-1.8 band. The assumptions underlying the medium variant of the United Nations population projections (Table 1) are completely consistent with this approach. By European standards fertility of about 1.9, as in France and the United Kingdom, is comfortable albeit below replacement level. The medium variant is based on the assumption that in the lowest-low fertility countries (such as in Germany and in Italy), period fertility will increase monotonically until it reaches 1.5-1.6 in 2030-2035 (the last relevant period for our projections). 
Figure 1:

Period total fertility rate, $1950-2007$

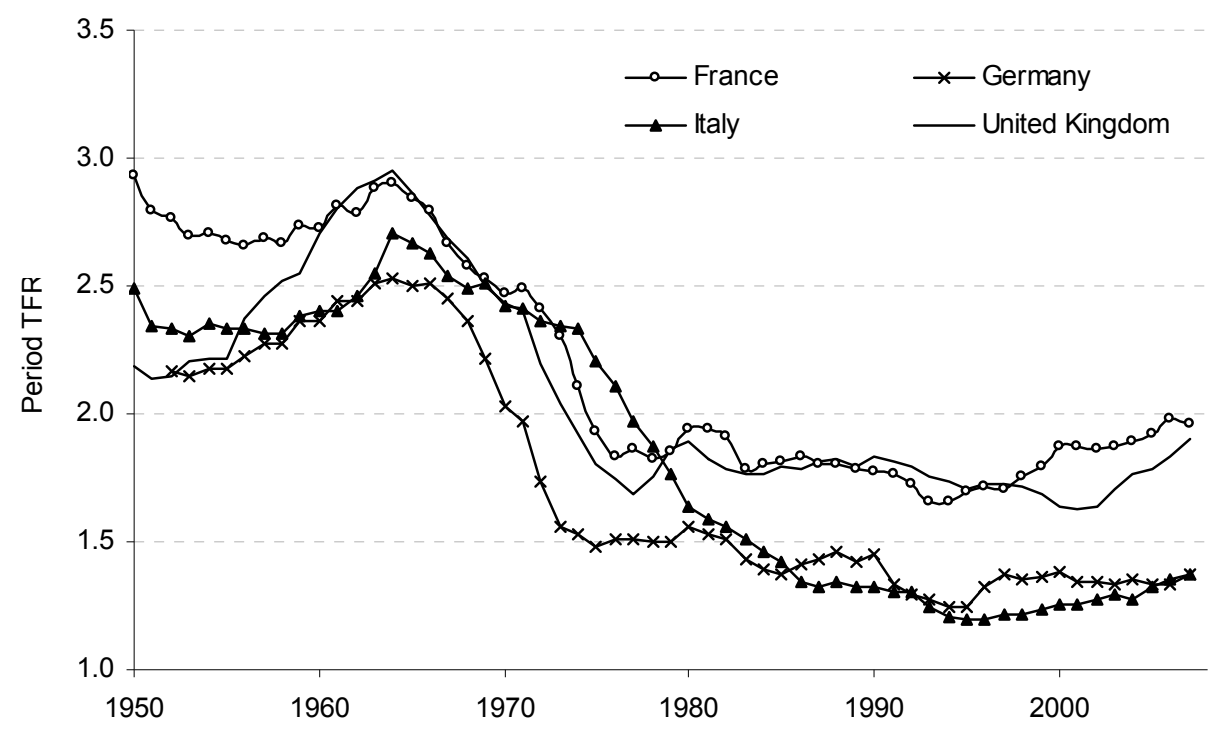

Source: Eurostat online statistics database and national statistical offices

There are no reasons to expect them to rise in the future beyond diminishing tempo effects. In contrast, Italy and Germany sank to the depth of fertility bust: in the mid-1990s TFR in both countries declined to 1.2. In Italy, TFR remained below 1.3 for more than a decade.

Until recently, the prevailing expectation was that lowest-low fertility is likely to last several decades (Kohler et al. 2006), because the decline of period rates was not limited to a transitory tempo effect but also fuelled by a contracting quantum. In fact fertility trends have reversed recently in low fertility countries. Fertility has risen in Germany, Italy and the United Kingdom and to a lesser extent in France.

Such increases are compatible with the analyses of period-cohort interaction effects of postponement (e.g. Sobotka 2004) as well as the plausible immigration from the higher-fertility countries, even though these effects are not explicitly factored in. In the medium-low fertility countries, period fertility will change only marginally: by decreasing by 0.04 in France and by increasing by 0.01 in the United Kingdom. The difference between the high and the low variants is one child per woman, while the medium variant is equidistant from the extremes. 
Demographic and economic factors of labour supply

Table 1:

Period total fertility rate according to United Nations Population Estimates and Projections, 2008 Revision

\begin{tabular}{|c|c|c|c|c|c|c|c|}
\hline \multirow{2}{*}{$\frac{\text { Country }}{\text { Germany }}$} & \multirow{2}{*}{$\begin{array}{l}\text { Variant } \\
\text { Constant fertility }\end{array}$} & \multicolumn{6}{|c|}{$2005-20102010-20152015-20202020-20252025-20302030-2035$} \\
\hline & & 1.32 & 1.32 & 1.32 & 1.32 & 1.32 & 1.32 \\
\hline & High & 1.32 & 1.59 & 1.79 & 1.94 & 1.99 & 2.04 \\
\hline & Low & 1.32 & 1.09 & 0.99 & 0.94 & 0.99 & 1.04 \\
\hline & Medium & 1.32 & 1.34 & 1.39 & 1.44 & 1.49 & 1.54 \\
\hline \multirow[t]{4}{*}{ France } & Constant fertility & 1.89 & 1.89 & 1.89 & 1.89 & 1.89 & 1.89 \\
\hline & High & 1.89 & 2.10 & 2.25 & 2.35 & 2.35 & 2.35 \\
\hline & Low & 1.89 & 1.60 & 1.45 & 1.35 & 1.35 & 1.35 \\
\hline & Medium & 1.89 & 1.85 & 1.85 & 1.85 & 1.85 & 1.85 \\
\hline \multirow[t]{4}{*}{ Italy } & Constant fertility & 1.38 & 1.38 & 1.38 & 1.38 & 1.38 & 1.38 \\
\hline & High & 1.38 & 1.66 & 1.84 & 1.99 & 2.04 & 2.09 \\
\hline & Low & 1.38 & 1.16 & 1.04 & 0.99 & 1.04 & 1.09 \\
\hline & Medium & 1.38 & 1.41 & 1.44 & 1.49 & 1.54 & 1.59 \\
\hline \multicolumn{2}{|c|}{ United Kingdom Constant fertility } & 1.84 & 1.84 & 1.84 & 1.84 & 1.84 & 1.84 \\
\hline & High & 1.84 & 2.10 & 2.25 & 2.35 & 2.35 & 2.35 \\
\hline & Low & 1.84 & 1.60 & 1.45 & 1.35 & 1.35 & 1.35 \\
\hline & Medium & 1.84 & 1.85 & 1.85 & 1.85 & 1.85 & 1.85 \\
\hline
\end{tabular}

Source: United Nations, DEMOBASE

Immigration from higher-fertility countries of the South lifts, sometimes significantly, fertility levels in the receiving countries. The average fertility of foreign-born women is typically higher than that of native women (Toulemon 2004) and sometimes even higher than the average level in their country of origin (Haug et al. 2002). Larger flows of immigration from the South would, therefore, impact on receiving populations directly by adding inhabitants, and indirectly by disproportionately increasing the number of births. This effect is not factored into the United Nations population projections, where immigration is not apportioned by sending countries and the fertility rates of the receiving country are instantly applied to the newcomers.

The observation that in selected developed countries fertility trends have recently reversed has prompted more audacious explanations. According to Myrskylä et al. (2009) the j-shaped curve that relates total fertility to the human development index, implies that at the highest edge of socio-economic development fertility tends to increase more and faster than the rate factored into the medium variant of the United Nations projections. This hypothesis focuses on period fertility and is based entirely on the underlying assumption that development raises the number of wanted children, rather than on the evidence of postponement-recuperation effects or impacts of immigration from higher fertility countries. Micro-level studies suggest that fertility desires have somewhat strengthened in certain most advanced countries, but in a more restricted magnitude than needed for replacement. This results from childbearing-friendly 
societal conditions, rather than merely from the improvements in wealth, health and education that are captured in the human development index. This is why this ascending trend is not universal and it may be wiser to assume that fertility in Italy and Germany could increase more than factored into the medium variant of the United Nations projections only as a result of sustained and successful policies.

\section{Migrations}

With respect to immigration, a consistent series of estimates of an acceptable quality (albeit of different length) are available for all four countries (Figure 2). By contrast, emigration data are available only for Germany and the United Kingdom; however, circumstantial evidence and indirect estimates of emigration allow estimating the trends of net migration for all four countries.

During the three decades after World War II, France was a net recipient of migrants with mostly flat and low (in comparison with the country's population) levels, which were interrupted by hikes following the end of colonial rule in Indochina and Africa. Net migration for the other three countries during that period was erratic. Out-migration prevailed and the sign and volume of net migration were determined mostly by emigration. The situation changed since the 1980 s, as immigration surged in all four countries. Net migration to Germany attained its peak in the first half of the 1990s with massive waves of migrants from the former Soviet Union; it has since subsided. A similar surge of immigration fuelled by strong inflows of migrants from the South happened in Italy a decade later; it is unlikely to run out unless limited by the policies of the host country. Net-migration to the United Kingdom was increasing steadily (albeit not as abruptly) essentially because of the large influxes of immigrants from the Commonwealth and later from eastern Europe. France has also experienced a brief hike in the first half of the 2000s.

International migration already assumes the primary role in population reproduction. Since 1980, the net migration inflow into Germany has reached 6.9 million persons; during the same period, net immigration has added 4.3 million people to the population of Italy. Without these inflows of migrants, WAP would have started to contract much earlier and its current size would be smaller than it actually is (4 per cent in Germany and 8 per cent in Italy).

In 1996-2006, the total population of France was growing at an annualised rate of 5.7 per thousand; net migration contributed three-quarters to this growth. In Germany and Italy, the positive net migration overcompensated for the negative natural increase and secured a slow total population increase in Germany (0.6 per thousand per year) and a rapid growth in Italy (4.8 per thousand) (OECD 2009). By 2006 the share of the foreign-born attained 8 per cent in France, 10 per cent in the United Kingdom and 13 per cent in Germany. Undoubtedly, labour 
migration has an even greater impact on the reproduction of WAP, since migration inflows tend to consist primarily of workers.

With respect to international migrations, the past is not a particularly robust predictor of the future. Unlike fertility and mortality, migration has little inertia and is more responsive to direct public interventions. This is why migration assumptions are the weakest part of demographic projections. There is, however, no way around migration hypotheses for national populations. The United Nations postulates that the net migration will decrease during the next five years and then stabilise at (arbitrarily chosen) levels that are significantly higher than those prevailing before the recent hikes: 100,000 per year in France, 150,000 in Italy, 110,000 in Germany and 170,000 in the United Kingdom.

\section{Figure 2:}

Immigration, 1984-2006 (thousand per year)

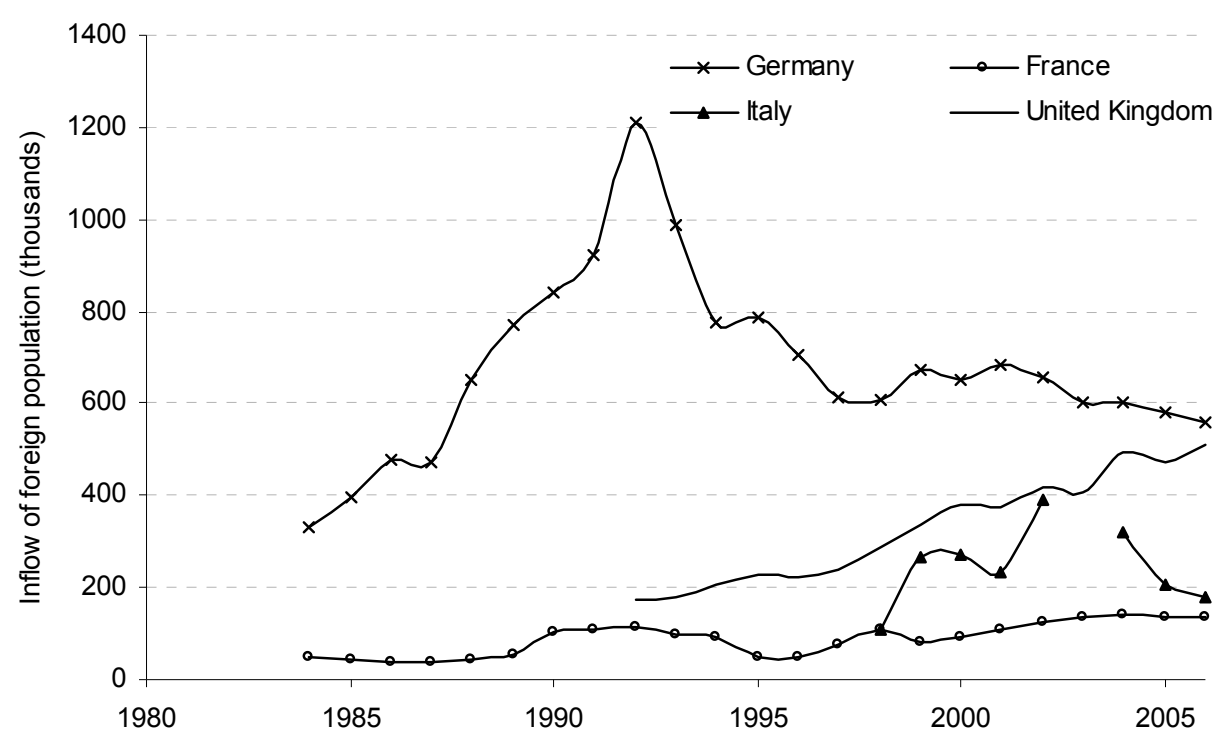

Note: Inflow data based on population registers

Source: OECD International Migration Outlook 2008 Edition, Table A.1.1

Purely as an arbitrarily adjusted extrapolation of the past, such an approach is as good as any alternative one. It is, in fact, based on a correct interpretation of international migrations as a product of so many short-term factors that it would be futile trying to foresee their developments even for the near future, let alone for decades from now. Instead of trying to do so, the extrapolative approach ignores the determinants of migrations and either freezes the (adjusted) absolute numbers, as is assumed in the United Nations projections, or selects a straight line as a trend. In either option, the increase of the role of migration (measured, e.g., by the 
net migration rate) in the population reproduction of below-replacement countries becomes a by-product of projections. Replacement migration approach is different. As will be demonstrated below, one should expect a strengthening need for immigration determined by long-term foreseeable demographic changes.

\section{Working-age population}

The standard age brackets of WAP (from 15 to 64 years) are adequate for the purpose of this paper. 15-17 year-olds are rarely employed since the youngest legal age at employment is 16 . On the other hand, internationally comparable data on the age group 18-19 are hard to find. Yet, it would be unwise to forsake the 15-19 age group altogether on the grounds that its majority is irrelevant for the task at hand. Undeniably, labour force participation of teenagers is decreasing as a result of universal enrolment in secondary education and the expansion of tertiary education, but it still remains non-negligible.

We have chosen the typical statutory age at retirement for men (65 years) as the upper limit of WAP. In fact, people (and women in particular) often do retire at younger ages. Yet, we retain the higher age as the upper limit of WAP because the recent trend has been toward increasing the statutory retirement age with the ostensible goal of retaining more seniors in the labour force. While this trend is likely to continue (as well as the trend of the gender gap to close), making elaborate hypotheses about the unfolding of this process is beyond the scope of this paper. Although non-negligible proportions of people beyond statutory retirement age do keep working, the decrease of LFPR after age 64 is steep.

The evolution of WAP in the second half of the past century was determined by relatively young yet ageing age structures, by the initially high but subsequently declining fertility, and by the ups and downs of migration flows. The resulting trends were those of uninterrupted yet decelerating growth until 1990 in Italy, until 2000 in Germany and until 2010 in France, while WAP in the United Kingdom keeps growing (Figure 3). From 1970 to 2010, WAP has increased by 28 per cent in France and by $10-17$ per cent in the other three countries. WAP is poised to fall precipitously in Italy and Germany. In France all demographics are smoother and so will be the contraction of WAP. In the United Kingdom the combination of high fertility and robust immigration will fuel the growth of WAP until the end of the projection period.

Combinations of fertility variants with different influxes of migrants yield instructive projections. For all four countries, net migration is assumed to be either nil or at the level factored into the United Nations population projections. For Germany and Italy, where WAP will be particularly affected by low fertility, an additional set of projections is run where net migration is assumed to remain at a level approximately sufficient to maintain WAP (third line in each panel of Table 2). 
If fertility remains at 1.8 children per woman and net migration at the levels assumed by the United Nations, then by 2025 WAP will decrease by a modest one per cent in France and increase by (an also trivial) 4 per cent in the United Kingdom. In the following quarter-century, nothing dramatic will happen either: WAP in France will lose just four more percentage points, while gaining four more in the United Kingdom.

During the next 25 years, migration will make a big difference for both countries and especially for the United Kingdom, where maintaining net migration at the current level (170 thousand per year) will assure healthy growth of WAP under all fertility assumptions, except for the low-fertility variant. Even there, however, WAP will lose only 3 per cent. By contrast, the zero-migration scenario yields a 20 per cent decrease of WAP.

Figure 3:

Population aged 15-64, 1950-2050 (index, 2010=100)

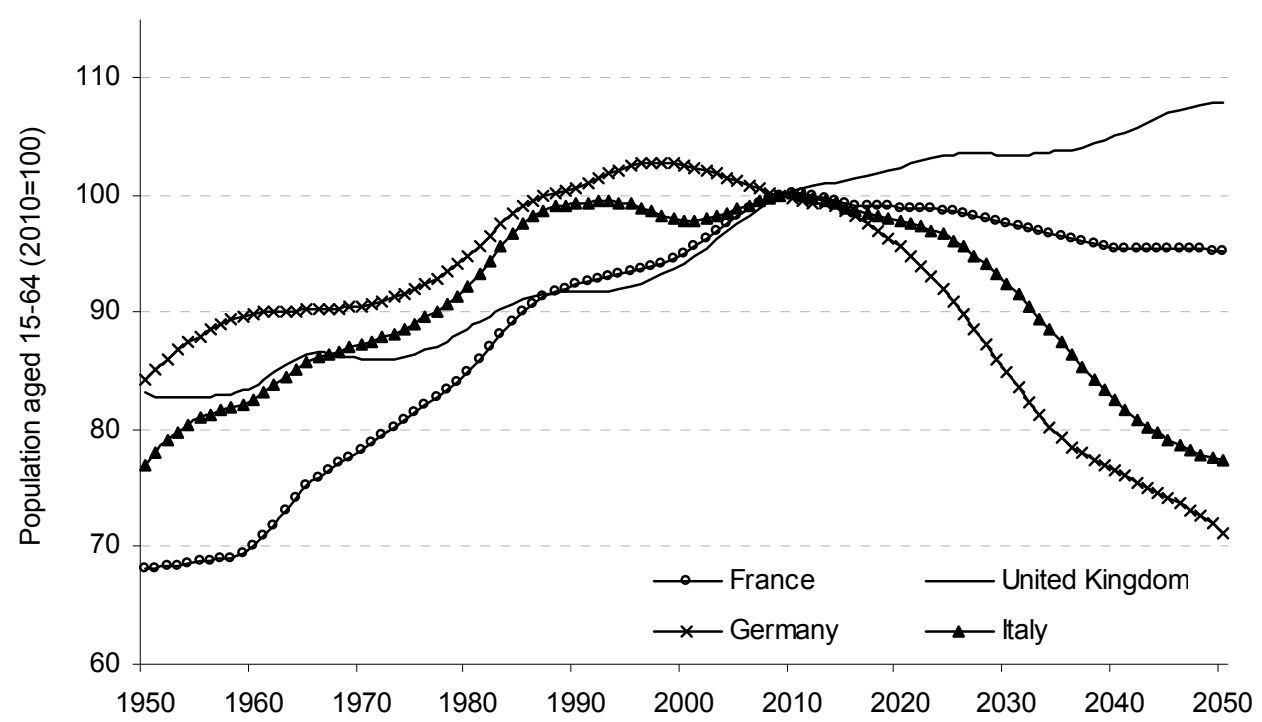

Source: United Nations, DEMOBASE (medium variant)

In France maintaining immigration at 100,000 per year could not prevent a mild contraction of WAP. In order to sustain WAP at the 2010 level, immigration ought to be increased by 30 per cent. If, on the other hand, net migration were to wear out, then by 2050 WAP is likely to decrease, though only by 10 per cent. This relatively low estimate is due to high fertility. The impact of migration on WAP is significantly lower in France than in the United Kingdom: the zero migration scenario produces, by 2050, a 6-percentage-point smaller WAP in France, compared with a 20-percentage-point difference in the United Kingdom. 
This is because net migration is much larger in the United Kingdom while fertility is slightly lower than in France. Yet in both countries, fertility significantly above replacement would be needed to completely offset the loss of migrant inflow.

Table 2:

Working-age population in 2025 and 2050, index $(2010=100)$, combinations of fertility variants and net migration (thousand per year) scenarios

\begin{tabular}{|c|c|c|c|c|}
\hline \multirow{2}{*}{$\begin{array}{c}\text { Net } \\
\text { migration }\end{array}$} & \multicolumn{4}{|c|}{ Fertility variant } \\
\hline & Low & Constant & Medium & High \\
\hline \multicolumn{5}{|c|}{ Germany } \\
\hline \multicolumn{5}{|c|}{2025} \\
\hline 0 & 89 & 89 & 89 & 89 \\
\hline 110 & 91 & 91 & 91 & 91 \\
\hline 1,060 & 102 & 102 & 102 & 102 \\
\hline \multicolumn{5}{|c|}{2050} \\
\hline 0 & 56 & 61 & 64 & 72 \\
\hline 110 & 63 & 69 & 71 & 80 \\
\hline 1,060 & 101 & 97 & 101 & 110 \\
\hline \multicolumn{5}{|c|}{ Italy } \\
\hline \multicolumn{5}{|c|}{2025} \\
\hline 0 & 91 & 91 & 91 & 91 \\
\hline $150^{\mathrm{a}}$ & 96 & 96 & 96 & 96 \\
\hline 330 & 101 & 101 & 101 & 101 \\
\hline \multicolumn{5}{|c|}{2050} \\
\hline 0 & 56 & 62 & 64 & 72 \\
\hline $150^{\mathrm{a}}$ & 69 & 75 & 77 & 86 \\
\hline 330 & 93 & 100 & 102 & 112 \\
\hline \multicolumn{5}{|c|}{ France } \\
\hline \multicolumn{5}{|c|}{2025} \\
\hline 0 & 97 & 97 & 97 & 97 \\
\hline 100 & 98 & 98 & 98 & 98 \\
\hline \multicolumn{5}{|c|}{2050} \\
\hline 0 & 79 & 90 & 89 & 99 \\
\hline 100 & 85 & 96 & 95 & 105 \\
\hline \multicolumn{5}{|c|}{ United Kingdom } \\
\hline \multicolumn{5}{|c|}{2025} \\
\hline 0 & 97 & 97 & 97 & 97 \\
\hline $170^{\mathrm{b}}$ & 103 & 103 & 103 & 103 \\
\hline \multicolumn{5}{|c|}{2050} \\
\hline 0 & 77 & 87 & 87 & 97 \\
\hline $170^{\mathrm{b}}$ & 97 & 107 & 107 & 118 \\
\hline
\end{tabular}

Notes: ${ }^{\text {a }} 220$ in $2010-2015,150$ thereafter; ${ }^{b} 188$ in $2010-2015,170-175$ thereafter Source: United Nations DEMOBASE 
Since the likelihood of zero migration and fertility declines to the levels currently observed in several European countries are rather modest in both countries, the natural reproduction of the labour force in France (with a moderate increase of immigration) and the United Kingdom (even provided that immigration somewhat declines) seems assured for decades to come.

Lowest-low fertility will, however, shape dramatic declines of WAP in Germany during the entire projection period and in Italy after 2025. Before 2025, no future fertility change can affect WAP. Provided that immigration continues at the current levels, by 2025 WAP will decrease by 4 per cent in Italy and 9 per cent in Germany. In case immigration stops, WAP will decrease by an additional 2 percentage points in Germany and by 4 percentage points in Italy.

Given the ingrained culture of lowest-low fertility in both countries, it is appropriate to concentrate, for 2025-2050, on two fertility variants: constant and slowly ascending paths (United Nations medium variant). The contraction of WAP will intensify strikingly after 2025 in either variant in both these countries. If total fertility remains there at current levels of 1.3-1.4 (Table 1) and migration continues as assumed by the United Nations, then the negative gap in WAP with respect to the levels in 2010 will widen to as much as 25 per cent in Italy and to 31 per cent in Germany. A gradual rise of the total fertility to 1.5-1.6 (United Nations medium variant) will make only a marginal difference of 2 percentage points, while ceasing migration will contract WAP by an additional 7 percentage points in Germany and by 13 percentage points in Italy.

In order to balance these losses, immigration to Italy should more than double, while in Germany the inflow of migrants should be increased ten-fold. The negative impact of past fertility trends is so powerful that even a fast-track fertility increase - starting immediately and leading to the total fertility rate at replacement level in the last relevant period (Table 1) - will not prevent WAP from declining by 14 per cent in Italy and by 20 per cent in Germany.

By replacement migration we understand the volume of net migration needed to offset labour shortages due to under-replacement of cohorts. The replacement migration paradigm is relevant for Germany and Italy, yet not so much for France and the United Kingdom. In the former country, just a modest increase of immigration will stabilise WAP, while in the latter even a slightly 'smaller than now' immigration would not lead to contraction.

\section{Participation in the labour market}

Not everyone of working age is able to work, wishes to enter the labour market, or actually has a job. Labour force participation (economic activity) and employment rates shape labour supply as much as demography does. Within the context of deteriorating demographics it is appropriate to focus on two issues: 
past trends of 'participation' indicators, current differentials and a potential for balancing the demographic decline.

\subsection{Dynamics of labour force: Demographic and economic components}

The aggregate levels of economic activity vary among countries, with the highest level claimed by the United Kingdom and the lowest by Italy (Figure 5). Until the early to mid-1980s, between 70 and 80 per cent of WAP in France, Germany and the United Kingdom participated in the labour force. Subsequently the trends diverged with gentle waves around the stable levels or slightly descending trends in Germany and the United Kingdom as opposed to a sharp decline in France. In Italy, for a long time the propensity for gainful employment has been as low as approximately 55 per cent, but from the late 1970s to around 1990 it gained 10 percentage points; then the trend inflected again and by 2007 LFPR went down below the low level of the 1970s. As a result the current LFPR range widely, from 50 per cent in Italy to 61 per cent in France to 75 per cent in the United Kingdom.

The shifts in the age structure may have a significant impact on the aggregate LFPR. Ageing depresses LFPR (Table 3) because it shifts the WAP's centre of gravity towards groups with lower participation rates. In 2000, the aggregate LFPR for WAP aged 15-64 varied from 62.5 per cent in Italy to 69.5 in France, to 75.6 in Germany, to 76.3 in the United Kingdom. Since then, ageing depressed the aggregate LFPR in France by 1.1 percentage points and in the United Kingdom by half as much. In Germany and Italy, what contributed to the increase of LFPR was the transitory rejuvenation of the WAP (echo of the baby boom). In the coming decades, the impact of the age structure on LFPR will be universally negative and substantive. This effect continues. As demonstrated by Carone (2005), by 2025 the ageing of the labour force will have depressed the aggregate LFPR by 3 percentage points in France and by 2 percentage points in Italy and the United Kingdom. If fertility follows an ascending path as assumed in the medium variant of the United Nations population projections, the impact will reverse some time during 2025-2050. These demographic shifts are pre-programmed by fertility, but they can be altered by immigration, which always contains a disproportionately large selection of the most economically active age groups.

The importance of demographic impacts on the aggregate level of economic activity notwithstanding, LFPR is driven essentially by economic factors. During the last four decades, increased economic activity in Germany and Italy was shaped by a contribution to labour force growth that was far larger than the contribution made by the growth of working-age population. In Italy, a strengthened aspiration for remunerative employment accounted for threequarters of the increase of labour force from 1984 to 2007 (Figure 4). An increased propensity to seek jobs contributed even more ( 87 per cent) to the growth of available labour in Germany. Moreover, a jump in the LFPR in the 
early 2000s coincided with the beginning of the negative growth in the WAP: the former overcompensated for the latter and thus prevented proper acknowledgement of the force of demographics. In France and in the United Kingdom, the demographic base of the labour force grew significantly stronger, while the levels of LFPR had seen a much smaller change.

Table 3:

Change in total labour force participation rates (per cent)

\begin{tabular}{lccccc}
\hline \multirow{2}{*}{ Country } & Total & $\begin{array}{c}\text { Due to changes in } \\
\text { age-specific LFPR }\end{array}$ & \multicolumn{2}{c}{ Due to shifts in age structure } \\
\cline { 2 - 6 } & $2000-2007$ & $2000-2007$ & $2000-2007$ & $2007-2025$ & $2025-2050$ \\
\hline France & 2.2 & 3.3 & -1.1 & -2.3 & 0.9 \\
Germany & 4.0 & 3.4 & 0.7 & -2.2 & -0.2 \\
Italy & 2.3 & 1.5 & 0.8 & -3.5 & 0.8 \\
United Kingdom & -0.1 & 0.5 & -0.6 & -0.5 & 0.2 \\
\hline
\end{tabular}

Sources: OECDStat, United Nations DEMOBASE

Figure 4:

Change of working-age population and labour force, 1984-2007 (per cent)

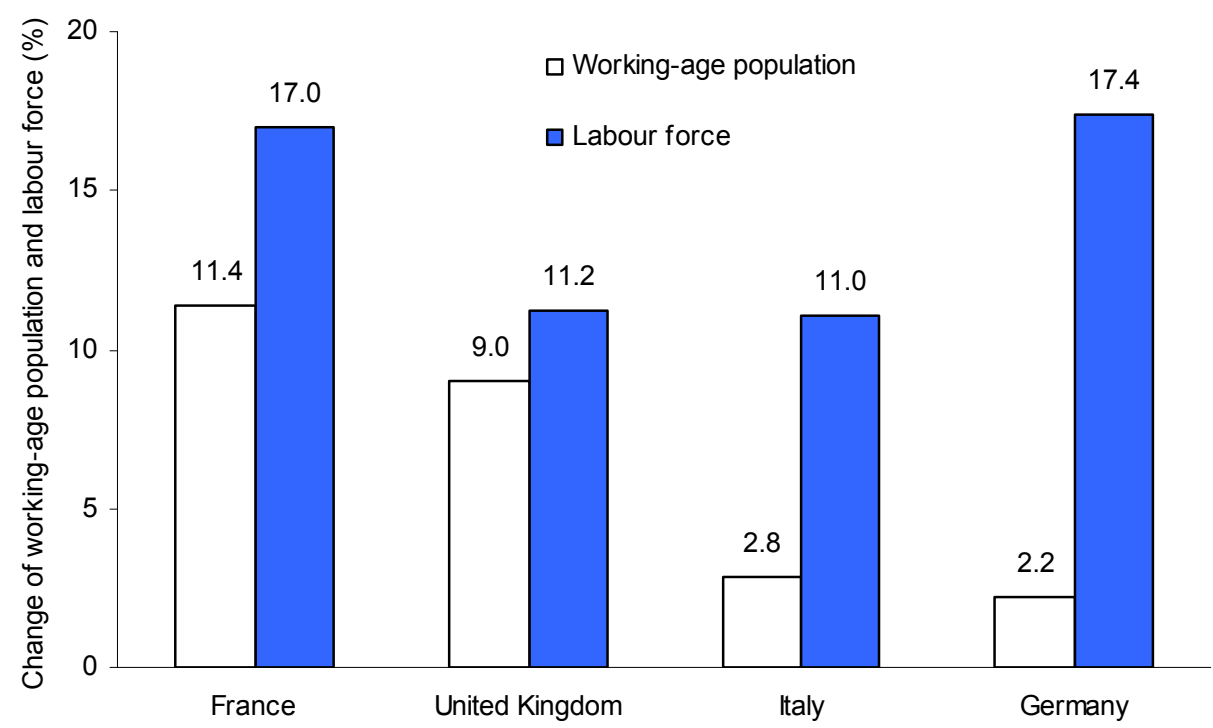

Source: OECDStat, United Nations DEMOBASE 
Neither the levels nor the trends of participation in the labour force are similar for different population groups. The clearest distinctions run along gender and age lines: everywhere the overwhelming majority of adult men are economically active, while fewer women seek gainful employment. Concurrently, the trends in aggregate LFPR are driven primarily by shifts in female labour. Among young people, work competes with education. Participation in the labour force declines around the statutory retirement age, although the push and pull factors shaping the economic activity of older persons vary. The trends of economic activity of these groups are not necessarily always oriented in the same direction; they have different demographic weights and, therefore, unequal inputs into the dynamics of the labour force.

It is not clear whether there is any systematic reserve in the participation of men of prime working age in the labour force. In France, in Germany and in the United Kingdom, more than 90 per cent of men in the age bracket 25-55 years either work or actively seek work. Italy is different, in that 20 per cent of men in their late twenties do not seek gainful employment, but the distinctions in the other age groups are marginal. Although the variation across age groups is low, the rates are not identical: there is a noticeable (albeit small) decrease after peaks in the thirties, which intensifies in the early fifties with the resulting 3-5 percentage point drop in the aggregate participation in the labour force (OECDStat). Combined with the demographic structural effect noted above, this is able to significantly depress the total LFPR for prime-age males.

\subsection{Economic activity of young persons}

The youngest age group (15-19) is 'exposed to the risk' of employment only to the extent that one's graduation from a mandatory education level typically happens before age 20. The percentage employed (and, by extension, economically active) may be significantly affected by the actual average age of university enrolment and gainful employment during summer vacation; these phenomena are country-specific and bring disturbances to the estimation of LFPR. According to OECD estimates, the average for France and Italy dropped from 41 per cent in 1970 to 13 per cent in 2007 (data for Germany and the United Kingdom are missing). In several developed countries, this proportion currently exceeds 50 per cent, which apparently implies that a large proportion of youth enters the labour market right after graduation from high school.

The first 'fully exposed' group includes youth aged 20-24, for which the general trend is towards increasing full-time enrolment in tertiary education at the expense of seeking full-time jobs on the labour market (Figure 5). This trend has intensified since the 1980s. In spite of significant inter-country differentials in levels and trends of youth involvement in the labour force, any sustained reversals are unlikely even when labour supply becomes significantly strained. 
Figure 5:

Labour force participation rate, age group 20-24, 1968-2007 (per cent)

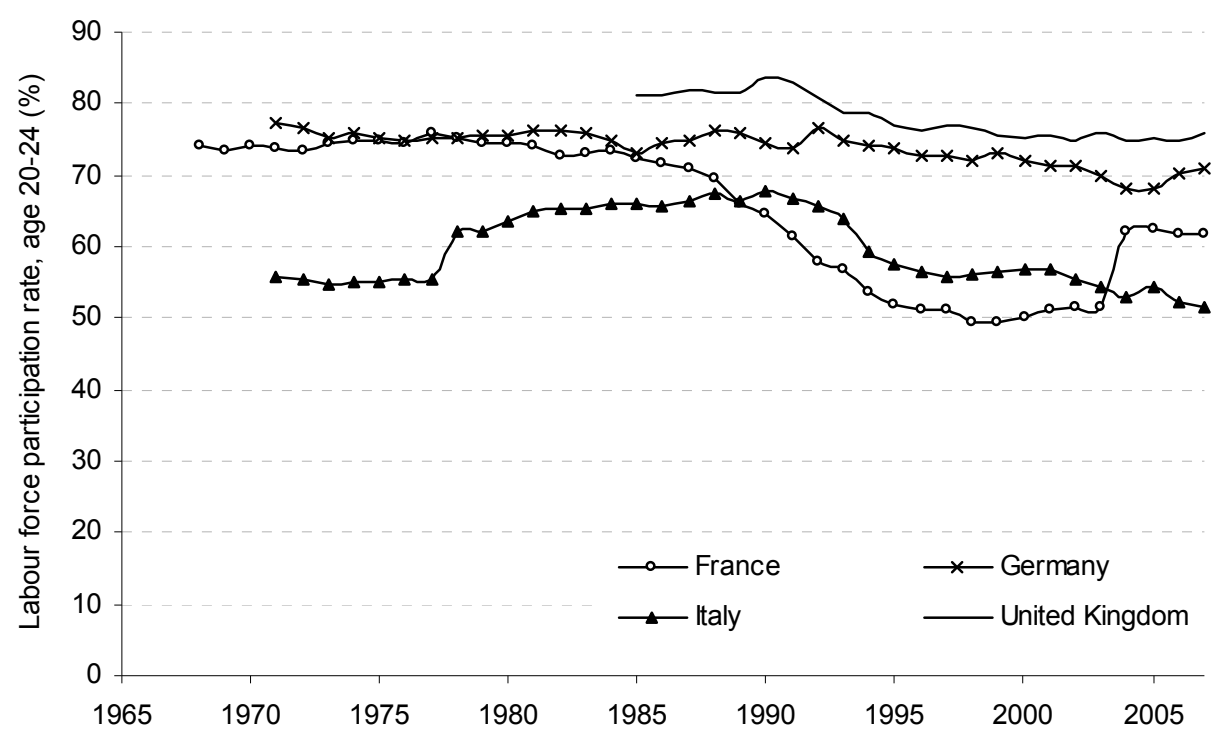

Note: In France, a break in series in 2005 happened because the source of data changed from one annual survey to a continuous survey; adjusted data are not available.

Source: OECDStat

\subsection{Economic activity of older persons}

The economic activity of older persons depends on a complicated array of factors. Most generally, much fewer older persons than persons of prime working age participate in the labour force. For instance, LFPRs in the age group 55-64 are at least twice lower than in the age group 25-54. How often men and women seek employment past their prime working age is determined by the statutory retirement age, pension-wage ratios, availability of re-training, part-time jobs, adaptive work environments etc. A cardinal, but difficult to measure, factor is the culture-specific relative value of leisure vs. income.

For men, the most common statutory age of pension entitlement is 65 , for women 60; in some professions retirement at the statutory age is mandatory. The average effective retirement age is typically lower for women (Table 4). The gap is particularly wide for men in Italy and for women in Germany. This implies that many people take advantage of a multitude of arrangements that allow taking early retirement with full pension entitlements. In many countries, large groups of older workers are opting for early retirement (Gruber and Wise 2002). The proliferation of such arrangements, coupled with an increased value of leisure and increased life-long savings has led to an effective lowering of the retirement age 
over the last 30 years. This is associated with decreasing LFPR in the age group 55-64 (Figure 6). The trend has meanwhile halted and even started to reverse, in response to a rising length of one's healthy life, coupled with stronger financial incentives for older people to work. The Survey of Health, Ageing and Retirement in Europe has shown that better health may account for as much as 10 percentage points higher participation rates for men and women aged 50-64 (Kalwij and Vermeulen 2005).

In order to keep the pension systems solvent and to effectively capitalise on the increased expectancy of healthy life, governments are adopting plans that aim to increase the statutory retirement age in small increments and to close the gender gaps. Thus, in the United Kingdom the retirement age will rise from 65 years for men and 60 years for women to 68 years for all; the process will start in 2024 for men and in 2010 for women. In Germany, the statutory retirement age for men and women is 65 years; it will increase by two years during 2012-2029. In Italy, the reform is short-termed and concerns women only, whose retirement age will increase, between 2009 and 2013, from 59 to 61 years, while no decision was taken regarding the retirement age for men (currently 65 years).

Table 4:

Average effective age at retirement and the statutory retirement age, 2002-2007

\begin{tabular}{lcccc}
\hline \multicolumn{1}{c}{ Country } & \multicolumn{2}{c}{ Men } & \multicolumn{2}{c}{ Women } \\
& $\begin{array}{c}\text { Average } \\
\text { effective }\end{array}$ & Statutory & $\begin{array}{c}\text { Average } \\
\text { effective }\end{array}$ & Statutory \\
\hline France & 58.7 & 60.0 & 59.5 & 60.0 \\
Germany & 62.1 & 65.0 & 61.0 & 65.0 \\
Italy & 60.8 & 65.0 & 60.8 & 60.0 \\
United Kingdom & 63.2 & 65.0 & 61.9 & 60.0 \\
\hline
\end{tabular}

Note: The average effective age of retirement is derived from observed changes in participation rates over a 5-year period for successive cohorts of workers (by 5-year age groups) aged 40 and over. Source: OECD estimates derived from the European and national labour force surveys.

While in Germany and the United Kingdom, raising the age at retirement conforms with the actual trends towards remaining economically active for a longer period (in the United Kingdom the participation rate of older persons jumped by 10 percentage points in 10 years), in France and Italy-where the national cultures value leisure time more - the opposite trend towards earlier retirement prevails.

In Germany, the start of the contraction of the working-age population coincided with a recent steep increase of older persons' participation in the labour force. It is rather speculative to deduce the latter trend from the former trend since the period is so short. In the long run, however, such a relationship is likely to appear. 
Postponing retirement (made possible by better health, and made necessary by the contraction of the WAP) constitutes a major reserve and a primary mechanism for society to adapt to sub-replacement fertility. Rising the statutory retirement age may have a strong impact on WAP dynamics because even a moderate increase in LFPR at the higher end of the age distribution will be magnified by the swelling size of the respective age groups.

\section{Figure 6:}

Labour force participation rate, age group 55-64, 1968-2007 (per cent)

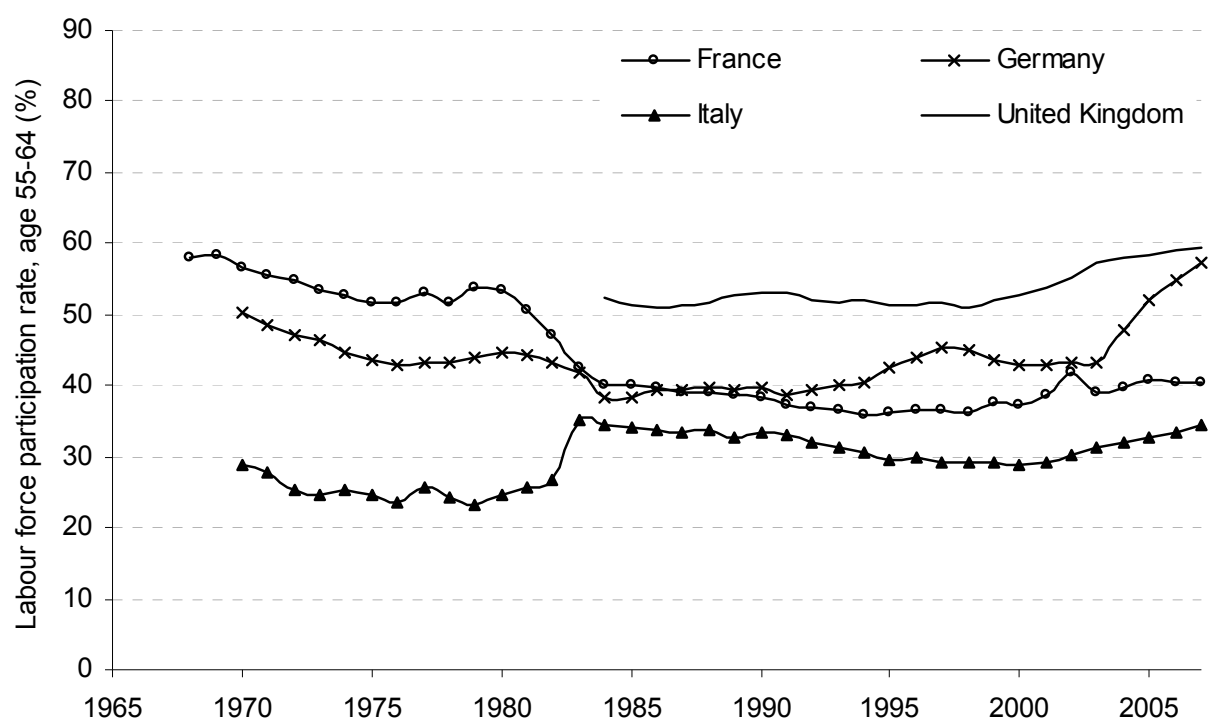

Note: In Germany, a break in series in 2005 happened because the source of data changed from an annual survey to a continuous survey; adjusted data are not available Source: OECDStat

These trends may be arrested by a growing attraction of leisurely lifestyles, supported by considerable pensions and life-long savings. The interplay of these forces promises to be complicated and long-lasting. This explains, at least partially, a 20-25 percentage point difference between labour participation rates of older persons in 'work-oriented' Germany and the United Kingdom on the one side, and 'leisure-oriented' France and Italy on the other (Figure 6). The opposite trends in France and Germany may stem from differences in the evolution of the labour markets.

\subsection{Economic activity of women}

Participation in the labour force is increasingly becoming the norm for women of all ages. This increase (Figure 7) has outweighed the reductions of economic 
activity of men and youth of both sexes. In the United Kingdom, the majority of working-age women had already belonged to the labour force as early as the 1970s, and by 2007 their labour force participation rate had attained 70 per cent. France, Germany and Italy underwent a genuine revolution in women's employment. From 1970, economic activity rates of working-age women increased in France by 17 percentage points, in Italy by 22 points and in Germany by 23 points. As a result, currently 65-70 per cent of women are part of the labour force in France, Germany and the United Kingdom. Italy's rate is still only 50 per cent, however. The gender gaps have narrowed everywhere, yet they are far from closing: the male-female differential of economic activity rates ranges from 9 percentage points in France to 24 in Italy. The Lisbon Strategy of the European Union admitted that a shortage of economically active women is a major weakness of the European labour market. Given that women constitute half of WAP, closing gender gaps (particularly in Italy) could narrow the deficits in the labour force caused by demographic factors, but in the long-term perspective could not eliminate them.

\section{Figure 7:}

Labour force participation rate of women, age group 15-64, 1968-2007 (per cent)

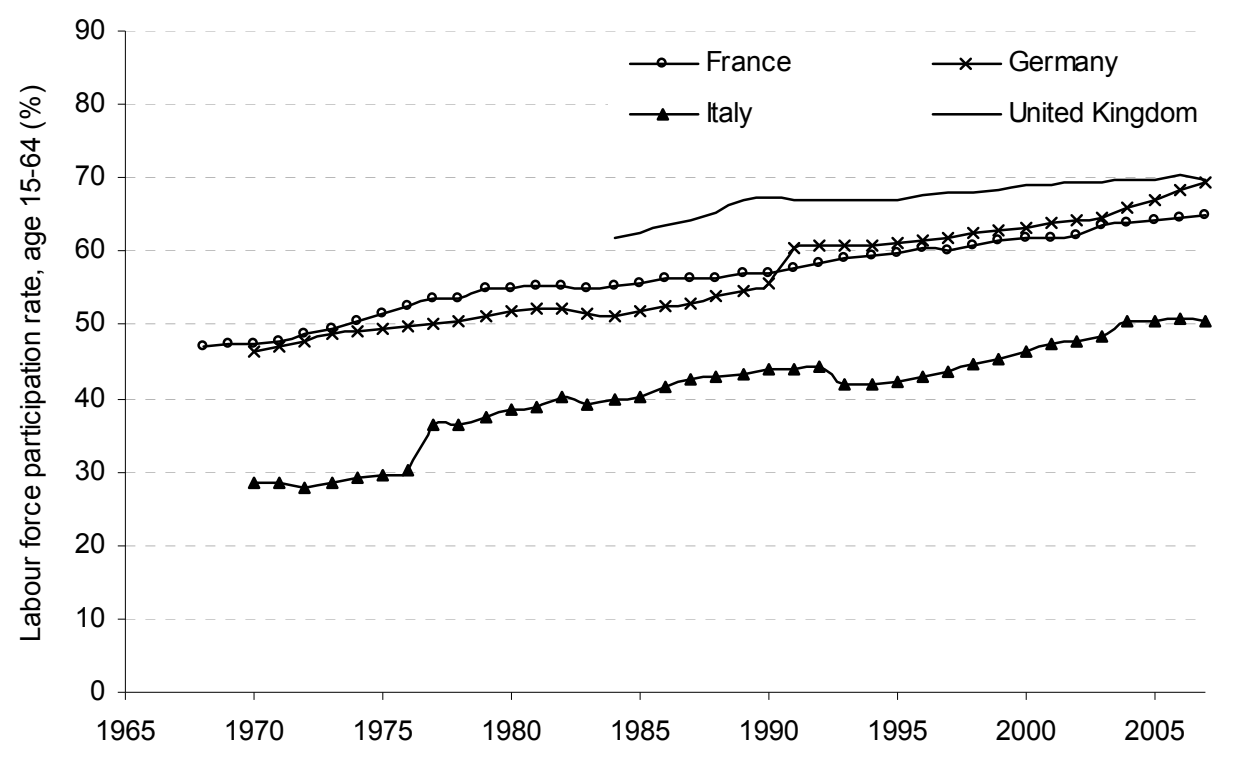

Source: OECDStat

Burniaux et al. (2003) looked at the potential of policies to balance the demographic impacts from the perspective of the aggregate LFPR, rather than that of the overall labour supply. They conclude that the combined effect of possible 
reforms targeting prime-age women, older workers and youth might suffice to stabilise LFPR until 2025 but will be insufficient to offset the additional reduction of participation likely to be caused by demographic changes beyond 2025. This is in line with our findings. Several studies have demonstrated, from a more sophisticated cohort perspective, that rising female participation rates may significantly, but not completely, offset the decline of WAP (Burniaux et al. 2003; Kok et al. 2003; Carone et al. 2005a).

\subsection{Unemployment}

It is the available workers that constitute the labour force. The extent of its actual use is determined by employment opportunities. During the after-war "glorious three decades", until the early 1970s, unemployment was typically below 3 per cent of the labour force. Since then, unemployment has risen tremendously in all four countries and the range of fluctuation increased to 6-10 per cent of civilian labour force (Figure 8).

\section{Figure 8:}

Unemployment rate as percentage of civilian labour force (1961-2008)

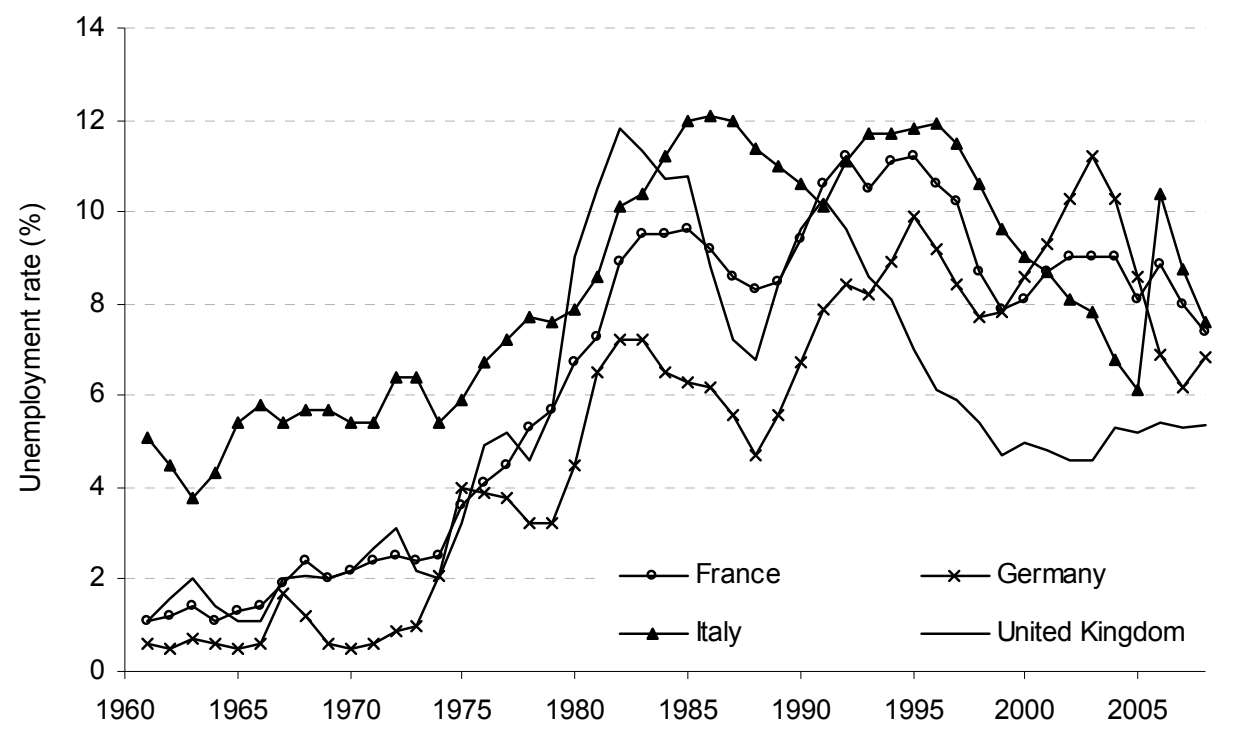

Source: OECDStat

It is not our goal here to dwell on the complex factors of unemployment. What we seek to reiterate is that high unemployment constitutes a capacious reservoir for replacing the labour force lost to demographic forces. Even in the United Kingdom, during spurts of burgeoning economic growth, unemployment 
was much higher than half a century ago; it has also been higher than the level that is deemed normal as a lubricator of economic change and a correlate of beneficial labour mobility. Some analyses conclude that in the European Union employment started increasing faster than WAP (Carone et al. 2005a), but it is unclear whether this is a reversal of the long-term trend or a cyclical phenomenon. One argument in favour of the systematic decrease of unemployment would be the contraction of the share in the labour force of youth (who typically suffer most from unemployment). Conversely, adding more persons aged 50 or older to the labour force-which certainly will be happening at least during our first projection period-may increase the aggregate unemployment rate, due to the fact that they are also disproportionately exposed to the risk of unemployment.

Sometimes the employment rate is defined as the proportion of employed persons in the WAP, rather than in the labour force (e.g. Feld 2006). In fact, the objectives to increase employment set by the Lisbon Strategy of the European Community are framed in this fashion. Such goal-setting appears easier to articulate, probably because more volatile ER trends are smoothed by more predictable LF trends. However, combining these fundamentally different phenomena may blur policy options, especially in the long term, and are definitely inappropriate to the goals of this paper.

\subsection{Cohort effects}

The continuation of the current rates of entry into, and exit from, the labour force of consecutive cohorts would produce significant impacts on the projected LFPR of certain age-sex groups, for women in particular (Carone 2005). Retaining this central assumption produces the cohort effects that would offset the demographic structural effects and expand the aggregate, especially in the first projection period (Table 5). The positive impact of cohort effects on period LFPR is expected to be particularly large in Germany and Italy, i.e. in the countries with highest declines of WAP.

Table 5:

Labour force participation rates in 2025 and 2050

\begin{tabular}{lccccc}
\hline \multirow{1}{*}{ Country } & 2007 & \multicolumn{2}{c}{ Constant-participation } & \multicolumn{2}{c}{$\begin{array}{c}\text { Constant entry-exit rates } \\
\text { scenario }\end{array}$} \\
& & 2025 & 2050 & 2025 & 2050 \\
\hline France & 69.2 & 66.2 & 66.7 & 71.7 & 73.1 \\
Germany & 71.3 & 71.1 & 71.5 & 78.7 & 79.0 \\
Italy & 61.6 & 59.4 & 60.7 & 68.1 & 70.2 \\
United Kingdom & 76.3 & 74.2 & 74.2 & 77.8 & 78.3 \\
\hline
\end{tabular}

Source: OECDStat and Carone 2005 


\subsection{Employed labour force}

Table 6 presents simulated relative changes, from 2010 to 2025 and 2050, of the number of employed in the national economy under one fertility assumption (medium level of United Nations projections), two variants of net migration (at constant levels assumed in the United Nations projections and without migration) and two employment scenarios that combine assumptions with respect to LFPR and ER. Scenario A uses the LFPRs from Carone (2005) which were obtained via a continuation into the future of the current rates of entry into and exit from of one-year cohorts. Employment rates are assumed to remain at their 2007 levels. Scenario B adds full employment.

The simulation results present a wide spectrum of futures. In all countries, high unemployment means significant reserves for balancing the adverse demographic situation.

The sustainment of the (recently intensified) entry into labour force of women, coupled with a stronger retention of older workers would more than offset - at the usual (2007) levels of unemployment - the decreases of workingage populations for the next 15 years in all four countries. Even without immigration the size of the employed population will either not change or will decrease only marginally. In addition, keeping immigration at the current levels will increase the labour supply, except in Germany. During that period, the dynamics of the employed population will be comparable with the trends in WAP in 1990-2005 when the issue of a contracting labour force was of minor concern.

Yet the age schedule in the working life of women may shift as a result of changing childbearing patterns. Hence, the assumption of continuity of entry-exit rates may not be entirely compatible with the assumption of a significant fertility increase in the currently lowest-low fertility countries (Germany and Italy). It is the latter assumption that served as the basis for the projections presented in this paper. In particular, a decrease of childlessness would be likely to lead to major changes in the entry-exit schedules. It is difficult to foresee, however, the extent and even the direction of change in every particular country because childbearing behaviour and childrearing-related patterns of employment depend on a myriad of cultural, institutional and social factors. Yet the stability of the labour supply under assumption used for scenario A may be fragile one.

Later on, the role of this factor will decline. Attaining full employment would significantly increase the labour supply. The trends in employed population in all four countries will be firmly ascendant, even without new immigration, and the increments of the labour force in Italy and the United Kingdom will be comparable with those during 1984-2007 (Figure 4). Moreover, complete eradication of unemployment by 2025 could increase the employment index by several points, which, ceteris paribus, will be sufficient to plug labour deficits in all countries save Germany. 
Table 6:

Labour supply in 2025 and 2050 under WAP, LFPR and ER hypotheses (employed labour force, index 2010=100)

\begin{tabular}{lcccc}
\hline \multicolumn{1}{c}{ Country } & \multicolumn{2}{c}{2025} & \multicolumn{3}{c}{2050} \\
& Employment scenarios & \multicolumn{2}{c}{ Employment scenarios } \\
& A & B & A & B \\
\hline France & \multicolumn{2}{c}{ Net migration according to } & United & Nations projections \\
United Kingdom & 102 & 122 & 100 & 118 \\
Italy & 105 & 112 & 110 & 117 \\
Germany & 106 & 130 & 88 & 104 \\
& 100 & 106 & 79 & 83 \\
France & & Zero migration & & \\
United Kingdom & 100 & 120 & 94 & 110 \\
Italy & 99 & 106 & 89 & 95 \\
Germany & 101 & 123 & 73 & 86 \\
\hline
\end{tabular}

Sources: United Nations DEMOBASE, OECDStat and LABORSTA (ILO)

In the following quarter-century the dynamics of labour supply in scenario A sharply diverge. The robust demography of France will secure the stability of that country's labour supply despite a modest level of immigration. Yet immigration would make the difference between stability and decline. In the United Kingdom the labour supply will increase by 5 index points under sustained immigration. If, however, immigration halted the employed population would dwindle to 89 per cent of its 2010 size. A stop in immigration would not even be entirely compensated by full employment.

The prospects of labour supply in the second quarter of the century will be more challenging for Italy and Germany. These countries have in common much larger negative impacts of protracted very low fertility, especially after 2025. Provided stable employment characteristics and continuous immigration, by 2050 the employed population will decrease by 12 per cent in Italy and by 21 per cent in Germany; in the absence of immigration, the decrease will attain 27 and 29 per cent, respectively. The eradication of unemployment will make a difference but would be largely insufficient to close the demographic gap.

In both countries the role of immigration in replenishing the labour force will increase from a modest one in 2010-2025 to a very substantial one by 2050, and in particular in Italy, where it will contribute from 15 to 18 index points to the dynamics of the employed population. Germany is likely to remain hostage to its demographics because the current level of immigration is by far insufficient to sustain (even in combination with full employment) the size of the employed population. Foreign labour also matters elsewhere because in the selected scenarios, immigration (at the volumes assumed by the United Nations) typically makes the difference between growth and decline of working populations. 
The results of our simulations are consistent with other analyses, yet they bring some additional insights on the role of the dynamics of the labour force, provided that the employment histories of cohorts remain unchanged under contrasting assumptions about international migration. Since the cohortcomponent method was applied by Carone (2005) with higher-than-in-the-past entry-exit coefficients, it necessarily leads to increasing LFPR, as cohorts are projected into the future. The method is convincing with respect to the feasibility of significant rises of the overall level of participation in the labour force.

The institutions of the European Union acknowledge that even if the Lisbon employment targets are met, overall employment levels will fall due to demographic change (European Commission 2005). This forecast is plausible on the EU average level and fully applies to Germany and Italy. The labour markets of France and the United Kingdom will benefit, however, from their better demographic dynamics. This underscores the utility of the country-specific approach when the strength of factors varies widely, and particularly so in demographic dynamics which are likely to become the most important determinants of the reproduction of the employed labour force.

\section{Utilisation of labour}

Those who have a job work different hours, have vacations of unequal length, enjoy a varying number of holidays and take uneven medical leaves. In the end, what matters most is the total pool of work hours available in the national economy.

\subsection{Levels and trends}

Labour utilisation (LU) varies across countries and changes over time (Figure 9). The general trend was a decline over a long period of time, but the monotony and speed of decline did vary. The largest decrease occurred in France where LU dropped by 22 per cent from 2011 hours in 1970 to 1561 hours in 2007, while the lowest occurred in Italy: from 1859 in 1980 to 1824 in 2007. The LU levels have diverged very significantly: the gap between the highest and the lowest levels soared from 3 per cent in 1970 to 27 per cent in 2007. In Germany, the decrease of LU since 1990 has more than offset the increase in aggregate employment. 
Figure 9:

Labour utilisation, 1967-2007 (annual hours worked per worker)

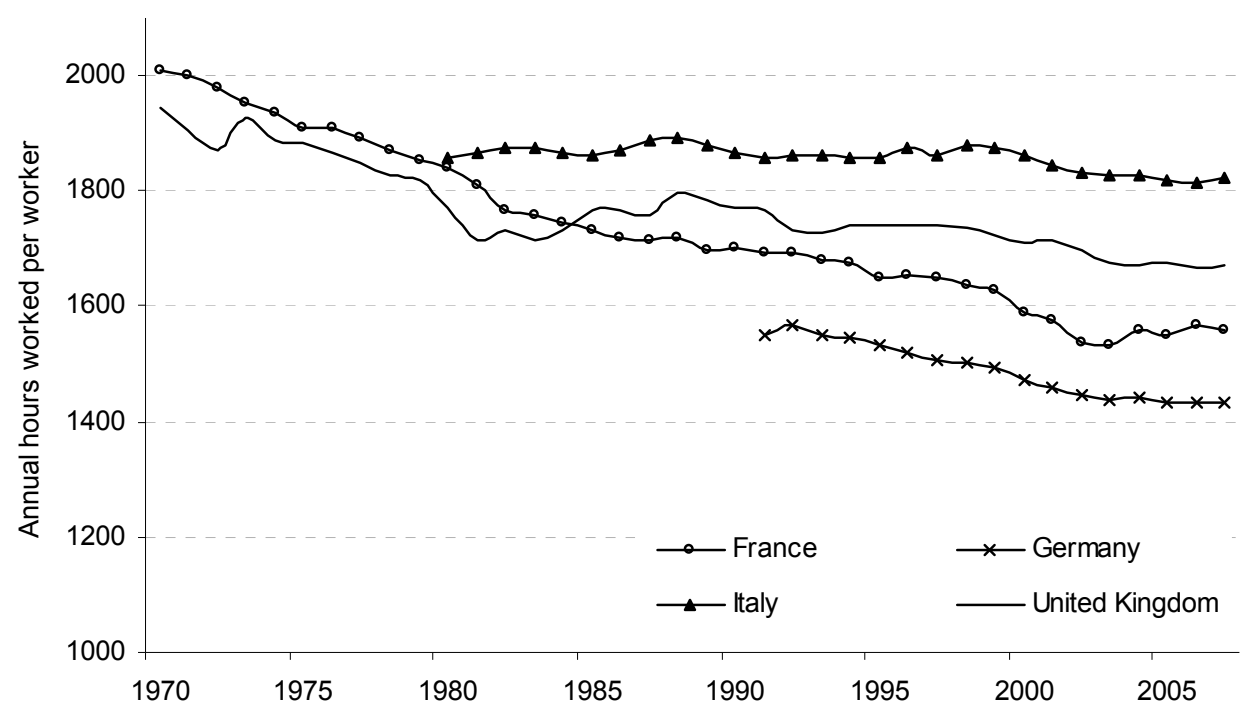

Source: OECDStat

\subsection{Working time}

The major factors of variation of LU are the length of the work week (measured in hours) and the length of paid vacation and paid holidays (measured in either calendar days or workday equivalents). Working time is subject to limitations by national law. The 2000 amendment to the Working Time Directive of the European Union of 1993 limits the maximum length of a working week to 48 hours in 7 days and a minimum rest period of 11 hours in each 24 hours. Legislations of many Member States provide for lower ceilings. In 2002, France had limited the statutory working week to 35 , although subsequently the regulations have been relaxed. In contrast, in the United Kingdom it is possible for several industries or professions to 'opt out' of the 48 hour working week.

Typically, national legislations allow exceptions for certain professions or occupations. Everywhere quite a few employees or self-employed work longer hours than the generally permitted maximum. Even in France 24 per cent of the employed aged 25 and more have actually worked more than 40 hours per week in 2007; in the United Kingdom this share was as high as 55 per cent; among them 24 per cent have worked more than 50 hours per week. On the other hand, many people prefer or are compelled to opt for either half-day employment or other contractual arrangements that result in shortened work weeks. The trends of the average hours worked (Figure 10) are driven by the shifts in these 
distributions. The average work week in the United Kingdom is 3.2 hours longer than in France (Figure 10), which translates into more than 150 hours difference in LU. During the last decade the actual work week was relatively stable in Germany and Italy, while decreasing significantly in Britain. In France the introduction of the 35-hour limit depressed the average work week below 38 by the year 2002 but subsequent legislative amendments have led to a one-hour increase.

Figure 10:

Average usual weekly hours worked on the main job, 1967-2007

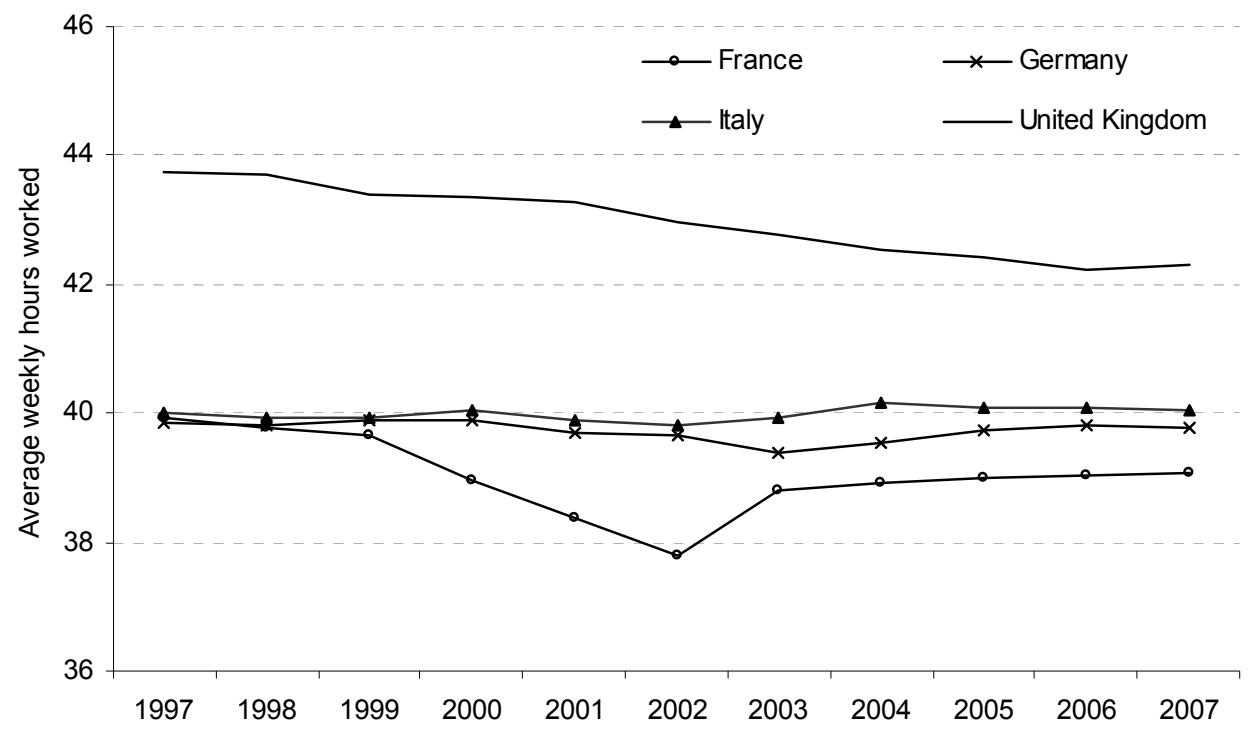

Source: OECDStat

There are other factors as well that determine the levels and drive the trends of LU. They include paid leave, national holidays, medical leave and time lost to labour disputes. Data on all these components are scarce, but paid vacations are perhaps the major factor in the variation of LU.

\subsection{Paid leave}

Most countries around the world have labour laws mandating employers to give to a worker a certain number of paid days off every year. Paid holidays are also regulated by law. There has been a long decreasing trend in the number of public holidays from several dozen in the Middle Ages to just a few by the beginning of the 20th century. Since then the trend has reversed again. In some countries, 
besides national holidays there are public holidays observed in subnational jurisdictions.

Considerable variations exist in the length of paid annual leave and paid public holidays across the developed states. The mandatory vacation time in the European Union is four weeks. The four countries under review are split into two groups: in France, Germany and Italy the entitlement varies from 31 to 34 working days, while in the United Kingdom it is one-third lower (20 days). Since LU is so much higher in Italy than in the other countries and the average workweek is about the same, many workers apparently take much shorter vacations - that is, unless strikes, sick leave and maternity leave account for the difference. The number of paid holidays varies, in the four countries, from eight in England (United Kingdom) to 13 in Saxony (Germany).

Similarly to the impact of the demographic structure on the labour force (Table 3), the age composition of the employed population influences LU: labour utilisation tends to be higher in younger populations. Boulhol (2009) has explicitly demonstrated that differences in population structure by age contribute importantly to the variations in LU.

\subsection{Total time worked}

Table 7 presents the simulation of total time worked (TT) through the application of labour utilisation (LU) assumptions to the combinations of employment and migration hypotheses discussed above. Both LU scenarios assume growth of LU (except in Italy in Scenario A) while the continuation of the current levels into the future is implicitly reflected in the scenarios of labour supply presented above. These LU scenarios represent a band of 'best practices'. Best-practice benchmarks make more sense than arbitrarily chosen values because they are the levels that have been actually recorded in the group of countries whose labour supply is simulated in this paper. This approach is also in line with the Open Method of Coordination for Social Policy adopted by the European Union (Pestieau 2006).

Variant I assumes that LU in Italy remains at 1825 hours per year (as observed in 2007), while meeting this level implies a growth of 9 per cent in the United Kingdom, 17 per cent France and 27 per cent in Germany. Even this relatively low option would call for profound changes on the labour market of France and the United Kingdom, yet such changes will be less needed there. Germany-due to the adverse demographics and the lack of potential in increasing labour participation-will find itself in the most challenging position.

In France and in the United Kingdom the raising of LU to the current Italian standard would ensure robust increases of labour supply even if unemployment remains high (Scenario A), provided that the recent increases in participation rates do not reverse and immigration is maintained. Combined with full employment (Scenario B), such an increase in hours worked would raise the labour supply by 
more than one-quarter in both countries throughout the entire projection period. Moreover, the intensified utilisation of labour in such magnitudes could largely offset the demographic effects, even if immigration were to cease.

Table 7:

Labour supply in 2025 and 2050 under migration, employment and labour utilisation hypotheses (total time worked, index $2010=100$ )

\begin{tabular}{|c|c|c|c|c|}
\hline \multirow{3}{*}{ Country } & \multicolumn{2}{|c|}{2025} & \multirow{2}{*}{\multicolumn{2}{|c|}{$\begin{array}{c}2050 \\
\text { Employment scenarios }\end{array}$}} \\
\hline & \multicolumn{2}{|c|}{ Employment scenarios } & & \\
\hline & A & $\mathrm{B}$ & \multirow{2}{*}{\multicolumn{2}{|c|}{$\begin{array}{cc}\text { A } & \text { B } \\
\text { aly, 2007) } & \end{array}$}} \\
\hline \multicolumn{3}{|c|}{$\mathrm{LU}=1825$ hours per worker per year (Italy, 2007) } & & \\
\hline \multicolumn{5}{|c|}{ Net migration assumed in the United Nations projections } \\
\hline France & 119 & 129 & 117 & 127 \\
\hline United Kingdom & 115 & 126 & 120 & 132 \\
\hline Italy & 106 & 113 & 88 & 94 \\
\hline Germany & 128 & 135 & 101 & 106 \\
\hline \multicolumn{5}{|c|}{ Zero migration } \\
\hline France & 117 & 127 & 110 & 119 \\
\hline United Kingdom & 108 & 118 & 97 & 107 \\
\hline Italy & 101 & 107 & 73 & 78 \\
\hline Germany & 125 & 132 & 90 & 95 \\
\hline \multicolumn{5}{|c|}{ LU=2011 hours per worker per year (France 1970) } \\
\hline \multicolumn{5}{|c|}{ Net migration assumed in the United Nations projections } \\
\hline France & 132 & 143 & 129 & 140 \\
\hline United Kingdom & 126 & 138 & 132 & 145 \\
\hline Italy & 117 & 125 & 97 & 103 \\
\hline Germany & 141 & 149 & 111 & 117 \\
\hline \multicolumn{5}{|c|}{ Zero migration } \\
\hline France & 129 & 141 & 120 & 131 \\
\hline United Kingdom & 119 & 131 & 108 & 118 \\
\hline Italy & 111 & 118 & 81 & 86 \\
\hline Germany & 137 & 145 & 99 & 104 \\
\hline
\end{tabular}

Note: Employment hypotheses are the same as in Table 6 Sources: DEMOBASE; OECDStat; EUROSTAT; LABORSTA

Assuming that LU in Germany rises to the Italian level and immigration does continue, during 2010-2025 that country's labour supply will be ensured, as well as in France or the United Kingdom, with or without immigration. During the following 25 years immigration will make all difference between stability and a precipitous decline. With immigration, the labour supply in 2050 will be 1-6 per cent larger than in 2010, while without immigration it would dwindle by 10 per cent. Even full employment would leave a 5 per cent gap. 
In Italy retaining the current relatively high level of labour utilisation would not prevent the labour supply from decreasing significantly (by some 12 per cent) by the middle of the century even if immigration is sustained and unless unemployment is substantially diminished. Halting immigration would be followed by a 27 per cent drop of labour supply; in this case even a complete eradication of unemployment could not prevent the labour supply from contracting by 14 per cent from its 2010 level.

Variant II is based on a higher benchmark of 2011 hours per year recorded in France in 1970. This assumption implies a 10 per cent increase in Italy, 20 per cent in the United Kingdom, 29 per cent in France and 40 per cent in Germany. Attaining it and retaining immigration would have closed all gaps created by adverse demographics in all four countries, except for in Italy in the 'unemployment-as-usual' scenario. In the zero-migration scenario the gap in Italy would reach 14-19 percentage points.

Some concluding observations can be made. The differentials in fertility that may seem trivial on the scale of a secular demographic transition determine a wide diversity of labour force trajectories. The half-a-child difference in fertility rates results in strikingly different dynamics for the working-age population. For France and the for UK, the decline in fertility has been sufficiently weak so as to sustain the 2010 workforce well into the future, even if at current low levels of immigration and without any changes to participation, employment or hours worked.

By contrast, the labour force is bound to shrink rapidly in lowest-low fertility Germany and Italy unless it is offset by either immigration sustained at unrealistically high levels or by drastic changes in the features of the labour market. Assuming that fertility will follow medium (slowly ascendant) paths, by the mid-century WAP in Italy and Germany will fall by 25-39 per cent. Moreover, the existing age structures in both countries make it impossible to stabilise WAP, even if fertility were to start increasing more rapidly (high variant). The negative impacts of medium-low fertility in France and the United Kingdom are several times weaker.

The observed (and then the extrapolated into the future) entries into and exits from the labour force (Carone 2005) yield LFPRs (Table 5) that are sufficient to offset small demographically-induced dents in the labour force in medium-low fertility countries like France and the United Kingdom, yet they are not sufficient to offset the large-scale contraction of the working-age population in the lowestlow fertility countries Italy and Germany. Immigration and eradication of unemployment could close the gap during 2010-2015, though not in the following quarter-century when Italy would need to increase the hours worked per worker by about 10 per cent and Germany by more than one-quarter. The simulations suggest that immigration is likely to increase and acquire new functions as a compensatory mechanism for population decline and as the alternative to adjustments through more intensive utilisation of labour. 


\section{Policy options}

Public policies are able to affect all components and factors of the labour supply that have been reviewed above. The adverse demographic impacts can be alleviated by labour market reforms or, alternatively, by increased immigration. However, this is not the case everywhere.

In these hard economic times, all four countries reviewed here are tightening immigration rules in order to 'protect' the labour market. How soon these policies will reverse is pure guesswork: the resumption of economic growth may not suffice because certain attitudes tend to take root. Yet, they are most likely to reverse themselves in the future, a change driven by demographically induced labour deficits that cannot be alleviated by economic adjustments alone. This is a long-term process, but one which could be accelerated given the necessary constellation of intervening factors.

\subsection{Immigration}

International migration already makes a huge difference in the reproduction of the labour force. Closing demographic deficits with increased numbers of migrants is realistic when the deficits are moderate, as in France and the United Kingdom. But wherever lasting low fertility rates create very large shortages of WAP - such as in Germany and Italy - balancing them with commensurate immigration is clearly unrealistic. For instance, for Germany this would entail having to allow in, absorb and integrate more than one million migrants per year. This would be almost ten times larger than the current stream and on a par with legal immigration in the United States (whose population is almost 4 times larger). Börsch-Supan (1998) came to a comparable conclusion: that Germany requires annual net migration of 800,000 , and over several decades, to stabilise the pay-asyou-go pension system. Massive arrivals in the early 1990s have attained this magnitude, but only for few years; it is much more difficult to conceive sustaining such immigration year after year and decade after decade.

Governments protect native labour force from competition and their national culture from erosion. They are mindful of many problems associated with immigration and therefore reluctant to 'throw the doors wide open'. Yet, immigration is an established and large-scale phenomenon. Streams of economic migration do enter the four countries from varied directions as supply of labour does not satisfy demand in different economic sectors and professions. Unsatisfied demand may arise on the lower levels of the professional ladder where natives are reluctant to take certain low-pay or 'degrading' jobs or where technical skills are in short supply. Governments have experimented with different regulatory mechanisms aimed at resolving short-term problems with short-term solutions. Some interventions proved successful, while others created more problems than they solved. In most countries, official positions on 
international migration, goal-setting and implementation have evolved into exceedingly complex, incoherent and sometimes contradictory policies, which, in addition, do not take into account unintended consequences of actions. Even when particular elements are sensible and effective, the entire mechanism often fails.

Current economic problems do differ from long-term demographic declines and such declines will not happen everywhere. Most likely, France and the United Kingdom will be spared the contraction of WAP, while Germany and Italy are going to see it on a large scale. Coping with large-scale and prolonged contraction of the labour force is a new challenge. The institutions of the European Union have embarked on a new path that envisages more sustained immigration flows required to meet the needs of the EU labour market (European Commission 2005). While increased immigration may significantly attenuate labour shortages, eventual massive streams of migrants will exacerbate the pressure on social security nets. Cultural environments need serious restructuring because their current abilities to absorb and integrate migrants are inappropriate even for actual stocks of migrants (European Commission 2005a). Otherwise, large increases of immigration may swell the numbers of the unemployed and socially excluded. The necessity to increase immigration requires rethinking the entire paradigm of what is good and what is bad for the nation, as well as what should be the tradeoff between preserving the national identity and developing multiculturalism.

The European Union is building a Union-wide space for free movement of workers. This is inherently good for a number of reasons, especially from the perspective of individuals. But from the macroeconomic supply-demand perspective of labour, facilitating the redistribution of labour within the Union is controversial. The economic differentials between the newly ascended Member States and the EU-15 create strong push-pull factors. Unlike in the demographically expanding past, mass migration under the new demographic regime leaves little place for win-win outcomes. Since in the demographic sense there are no labour-surplus countries in Europe-only different degrees of shortage-East-West migrations within Europe Without Borders will result in zero-sum results, spelling additional hardships for the less developed economies of sending countries. Since all these countries (except Poland) are small, draining them of labour force would make big dents in their labour markets without considerably attenuating the labour shortages in the receiving countries.

Currently, the trend is towards restricting the access of non-Union nationals to the EU countries and to labour markets. Immigration criteria are tightening and the application of the European rules against illegal migrants is emphasised. The future may be cardinally different when opening the European Union to migrants from outside will become necessary to compensate for future WAP deficits.

Migration from the low-fertility European countries to the east of the Union may be advantageous for the receiving countries, because of cultural proximity and better prospects for integration in the host societies. But the demographic consequences for the sending countries may be as negative as for the new 
members of the Union. Since all of them, and especially the largest, Russia and Ukraine, are demographically as weak as are the weakest populations of the Union, large and lasting emigration flows will be akin to a zero-sum game with the senders being the losers.

While human resources in Europe are limited and will become increasingly scarce, they are plentiful in the South. In terms of demographic potential, WAP increments in Turkey alone over the period 2010-2050 would be sufficient to compensate for one quarter of the WAP decrease in all of EU-25.

\subsection{Adjustments of the labour market}

Increasing participation in the labour market and the reigning in of unemployment constitute effective, attractive and possibly the most feasible options in reversing the decrease of labour supply. If recent increases of the participation of women and people past prime working age underwent a reversal, and unemployment remained as high as it is now, then the only means to prevent steep declines of available labour would consist of increasing immigration tremendously and, in fact, unrealistically.

Increasing the utilisation of labour is also an option but, for many reasons, is difficult to implement. The arithmetic of the issue highlights that France and the United Kingdom do not have much of a need to resort to such an approach. By contrast, Germany and Italy would need it even if efforts to increase employment were successful.

A diminishing supply of labour will press employers to embrace new policies with respect to persons past prime age, as well as to attract more female labour. Overall, development strategies already contain elements of the new vision as well as concrete recommendations aimed at necessary changes on the labour market. For instance, the core goals of the Luxembourg process aimed at adapting labour market policies in the European Union to the new technological and economic environments do conform to the actions arising from the need to adjust to the shrinking labour force.

Labour force participation and employment rates react to public policies through varied channels. For instance, excessively stringent employment protection legislation tends to reduce the dynamism of the labour market, worsening employment prospects for women, the young and the elderly (European Commission 2006).

Economic activity of men of prime working age is universally high, changes little over time, and has very limited growth potential. On the other hand, female participation in the labour force has increased ever since World War II; it varies across countries but is still much lower than the participation of men everywhere. The economic activity of women is elastic and responsive to a plethora of factors, including those that are amenable to direct government intervention, such as actions aimed at reducing the discrimination in the area of career development or 
at improving the compatibility of work and child care. Concrete incentives for women to work, recommended by the OECD for Germany, include reducing fiscal impediments to full-time female labour force participation by lowering the tax burden for second-earners and by introducing a health insurance charge for non-working spouses (OECD 2009a).

Levels of economic activity vary at both tails of the age distribution. The participation of youth in the labour force is primarily the function of enrolment in post-secondary education, though it also depends on the availability of part-time jobs and the presence of relevant regulations; all factors which are amenable to public intervention.

The participation of persons past prime working age depends on a host of factors where the retirement requirements and the conditions are pivotal. Most European countries have passed legislation to gradually increase the statutory retirement age. The rationale consists of supporting the solvency of pension funds. This indicates that serious changes can be initiated to avoid problems that would occur beyond the lifespan of all those currently alive. Labour shortages may even strengthen the case for more increases.

Currently, the market is not particularly friendly towards the aged. This should change and is already changing, albeit slowly. Recent increases of LFPR of the relevant age groups constitute, most probably, the response to these changes. Looming deficits of younger labour are likely to motivate the employers to discontinue widespread practices of discrimination on the grounds of age and increase the abilities of their enterprises to absorb a more aged labour force. Public policies may greatly enhance the employability of older persons, promote flexible retirement and develop adaptive work environments.

Increasing the statutory retirement age should be complemented by other more subtle and complex measures aimed at improving the abilities of persons attempting a career change. Appropriate public polices in this domain will be in line with the international instruments on ageing that were developed with concern for the issue of ageing rather than labour deficits. There appears to be a need for new incentives that would encourage workers to defer full retirement and continue to work, whether part-time or full-time. If such policies complied with the needs and limitations of persons past prime working age they could strengthen their propensity to remain economically active.

On the other hand, those who want to be employed and actually do get a job work varied hours. Total annual time worked per worker in Italy is 27 per cent longer than in Germany. The distributions of workers by hours worked vary, which implies different incentives and opportunities for working part-time or overtime, as well as different amounts of time off. The mainstream trend was towards shorter working time: this trend has recently flattened but did not reverse. Legislative regulations to curtail any of the components that determine the overall time worked would presume serious shifts in public attitudes. However, a similar change with respect to retirement age may indicate that reversals, even on such 
sensitive issues, may occur, provided that the public is persuaded, that compensation is attractive and that the resulting change is gradual. Concurrently, easing the restrictive and rigid labour regulations may bring serious positive effects. Causa (2008) has demonstrated that in the OECD countries stringent employment protection of workers on regular contracts has negative impacts on hours worked by men, over and beyond its restraining impact on employment levels.

Adjustment policies may be facilitated or impeded by the nature of labour shortage; they may become closely interrelated through synergistic or blocking effects. For instance, labour shortages tend to increase the economic activity through higher wages. Concurrently, scarce labour supply is likely to strengthen the bargaining position of workers, in particular with respect to regulation of working time. Thus, systemic labour deficits are bound to obstruct efforts to realign the work regulations. Opening the door to immigration and relieving labour code rigidities are likely to act in the opposite direction.

Economic output is not determined by the volume of labour alone. Growth in GDP per capita can be decomposed into the growth of the volume of labour and labour productivity. The latter may be raised by substituting labour for capital through technological progress and by investments in labour through education and training. In principle, the potential of labour productivity growth as an offsetting mechanism for population decline is large. All other parameters held constant, the projected decrease of WAP in Italy and Germany from 2010 to 2050 (medium variant, with migration according to the United Nations assumptions) could be offset by annual labour productivity growth in the order of 0.6 per cent in Italy and 0.8 per cent in Germany. However, the social and economic costs of such balancing would be high. The average annual rates of labour productivity growth during 1970-2005 were 2.5 per cent in Italy and 2.7 per cent in Germany (Bassanini and Venn 2008). If these rates were sustained, 24 per cent of productivity growth in Italy and 30 per cent in Germany would be 'earmarked' to offset adverse demographic trends rather than contribute to improving living standards.

\subsection{Changes of reproductive behaviour}

Sub-replacement fertility levels in France and the United Kingdom are sufficiently high to ensure that future reduction of working-age population will be mild or nil. Lowest-low fertility in Germany and Italy, however, predetermines a contraction of the working-age population of such magnitude that mighty and bold efforts will be needed to prevent serious economic consequences. The good news is that these countries possess large adjustment potentials in different domains. In Italy, the participation in the labour force (and particularly that of women, though also of young men) may be seriously increased. In Germany the working time may be significantly lengthened. Both countries have accumulated 
experience in absorbing many migrants. However, country-specific best potentials would not necessarily be sufficient to close the demographic gaps. These gaps are very likely to become so wide as to require simultaneous transformations in many domains. With respect to many aspects of labour, social relations and lifestyles the demographic trends may push to a growing divergence between France and the United Kingdom on the one side and Germany and Italy on the other. This, in turn, may have implications for integrative processes in the EU space.

The debate on the feasibility of public interventions aimed at reproductive behaviour in the developed countries focuses on the ways and means to secure the transition from lowest-low to medium-high fertility. This debate typically refrains from discussing above-replacement fertility because its achievement is presumed to be unrealistic - which implies that the total fertility rates above 2.2 by the end of the projection period underlying the high variant of United Nations projections are beyond the expectations even of the optimistic participants in these debates. It follows that a rapid increase of fertility soon in the projection period in a magnitude sufficient to yield, by 2050, a significantly larger WAP than in the high-fertility variant should be construed as definitively unlikely. The medium variant of the United Nations projections is based on the assumption of gradual fertility increase in the countries with lowest-low fertility, including Germany and Italy. Although neither the mechanism nor the determinants of such increase are explicitly defined in the projection hypotheses, the realisation of the medium variant is implicitly predicated on the success of transformations leading to a more child- and family-friendly society.

Fertility-boosting population policy is a controversial topic in social sciences and policy making. France demonstrates that an array of pro-family and pro-child policies consistently implemented over a long period may be successful, resulting in an attained and sustained fertility level that is about half a child higher than in the lowest-low fertility countries. Similar lessons may be drawn from the family policies in the Nordic countries. Emulating these experiences is possible in principle, but this would involve mobilising considerable resources and, in some cases, promoting serious societal changes. Also, it would be imprudent to extrapolate the applicability of proven policies to further changes in reproductive behaviour intended to ascertain above-replacement fertility.

A key issue in the population policy debate is the compatibility of childrearing with gainful employment. The experience of several European countries demonstrates that success depends not only on the availability of affordable child care services, but also on gender equality in the family and in the workplace. The European Commission recognises that families must be further encouraged by public policies that allow women and men to reconcile family life and work (European Commission 2005a). Where these conditions are not met, there are opportunities to build them, which may result in higher fertility.

The case in point is Italy, where low labour market participation rates of married women coexist with low fertility. A likely explanation of this relationship 
involves the Italian institutional structure, particularly as reflected in rigidities and imperfections of the labour market and characteristics of the publicly funded child care system. These rigidities tend to simultaneously increase the costs of having children and to discourage the economic activity of married women (Del Boca 2002).

Fertility differentials between the most and the least gender-equitable lowfertility societies do not exceed half a child per woman but this gap is very substantial for demographic dynamics. The small part of it may eventually close itself due to the diminishing tempo effect, whereby previously postponed births take place. The larger part of the gap, however, results from so many complex factors and their interactions that at this point trying to encompass them all into comprehensive models seems to be an unrealistic enterprise. The hypotheses range from those that are overly optimistic (e.g. the approach underlying the demographic policies in the Russian Federation), to those that plainly refute the effectiveness of public interventions aimed at increasing fertility. For instance, recent findings demonstrate that even if all currently advocated family policies were introduced at once this would not necessarily lead to an increase in the number of births (Dorbritz 2004; van de Kaa 2006). This is partly due to the fact that in some societies, sub-replacement family size desires have already become entrenched in the young cohorts (Goldstein et al. 2003).

Joining the trajectory of moderately increasing fertility would, even in an optimistic perspective, require significant restructuring in the societies where lowest-low fertility is deeply ingrained, i.e. in Germany and in Italy. Even if this were to happen - and all economic scenarios outlined above presume that it will - the negative demographic impacts of what has already come to pass on the labour force still cannot be prevented. By the mid-century, these impacts will grow so large that, bar a miraculous jump of fertility levels, only a combination of profound labour and immigration reforms will be able to prevent labour demand from shrinking by double-digit percentage points. A half-a-child disparity in the total fertility rate between France and the United Kingdom on the one hand, and Germany and Italy on the other, does account for a large part of the difference in WAP dynamics for the entire projection period. The improvements in labour force participation and labour utilisation, as well as larger streams of immigration - which in Germany and Italy should be done to compensate for demographic decline - could be transformed in France and the United Kingdom into economic growth.

\section{References}

Bassanini, A. and D. Venn. 2008. "The Impact of labour market policies on productivity in OECD Countries.” International Productivity Monitor 17: 3-15.

Börsch-Supan, A. 1998. "Germany: A social security system on the verge of collapse." In: H. Siebert (ed.) Redesigning Social Security. Tübingen, JCB Mohr. 
Boulhol, H. 2009. "The effects of population structure on employment and productivity." OECD Economics Department Working Papers No. 684.

Burniaux, J. M., R. Duval, and F. Jaumotte. 2003. "Coping with ageing: a dynamic approach to quantify the impact of alternative policy options on future labour supply in OECD countries." OECD Economics Department Working Papers No. 371.

Carone, G. 2005. "Long-term labour force projections for the 25 EU Member States: A set of data for assessing the economic impact of ageing." European Commission DGEFA Economic Papers No. 235.

Carone, G., D. Costello, N. Diez Guardia, G. Mourre, B. Przywara, and A. Salomäki. 2005a. "The economic impact of ageing populations in the EU25 Member States." European Commission DGEFA Economic Papers No. 236.

Causa, O. 2008. "Explaining differences in hours worked among OECD countries: an empirical analysis." OECD Economics Department Working Papers No. 596.

Del Boca, D. 2002. "Low fertility and labour force participation of Italian women: evidence and interpretations." OECD Occasional Paper No. 61.

Dorbritz, J. 2004. "Demographische Trends und Hauptergebnisse der deutschen Population Policy Acceptance Study (PPAS)." Zeitschrift für Bevölkerungswissenschaft 29(3-4): 315-328.

European Commission 2005. Green Paper "EU Approach to Managing Economic Migration."

European Commission. 2005a. Green Paper "Confronting demographic change: a new solidarity between the generations."

European Commission. 2006. Employment in Europe 2006.

Feld, S. 2006. "European Union employment objectives for 2010 and international labour migrations." Genus LXII(3-4): 11-34.

Goldstein, J., W. Lutz, and M. R. Testa. 2003. "The emergence of sub-replacement family size ideals in Europe." Population Research and Policy Review 22(5-6): 479-496.

Gruber, J. and D.A. Wise. 2002. "Social Security and Early Retirement around the World: Micro-Estimation." NBER Working Paper No. 9407.

Haug, W., P. Compton, and Y. Courbage (eds.) 2002. The demographic characteristics of immigrant populations. (Population Studies 38). Strasbourg, Council of Europe Publishers.

Kalwij, A. and F. Vermeulen. 2005. "Labour Force Participation of the Elderly in Europe: The Importance of Being Healthy." Working Paper No. 1887. Bonn, Institute for the Study of Labour.

Kok, W., C. Dell'Aringa, F. D. Lopez, A. Elström, M. J. Rodrigues, C. Pissarides, A. Roux, and G. Schmid. 2003. Jobs, Jobs, Jobs. Creating more employment in Europe. Brussels, European Commission Employment Taskforce.

Kohler, H.-P., F. C. Billari, and J. A. Ortega. 2006. "Low fertility in Europe: Causes, implications, and policy options." In: F. A. Harris (ed.) The Baby Bust: Who Will Do the Work? Who Will Pay the Taxes? Oxford, Rowman and Littlefield Publishers. Inc., pp. 48-112.

Myrskylä, M., H.-P. Kohler, and F. Billari. 2009. "Advances in development reverse fertility declines." Nature 460: 741-743.

Organization for Economic Cooperation and Development (OECD). 2009. Society at a Glance 2009: OECD Social Indicators.

Organization for Economic Cooperation and Development (OECD). 2009a. Economic Policy Reform: Going for Growth. 
Pestieau, P. 2006. The Welfare State in the European Union: Economic and Social Perspectives. Oxford, Oxford UP.

Sobotka, T. 2004. "Is lowest-low fertility in Europe explained by the postponement of childbearing?" Population and Development Review 30(2): 195-220.

Toulemon, L. 2004. "La fécondité des immigrées: nouvelles données, nouvelle approche." Population et Sociétés 400.

Van de Kaa, D. 2006. "Temporarily new: on low fertility and the prospect of pro-natal policies." Vienna Yearbook of Population Research 2006: 193-211. 